On the Genesis of Spatial-Numerical Associations: Evolutionary and Cultural Factors CoConstruct the Mental Number Line

Elizabeth Y. Toomarian ${ }^{a^{*}} \&$ Edward M. Hubbard ${ }^{\mathrm{a}}$

a. Department of Educational Psychology, University of Wisconsin- Madison, 1025 W. Johnson St. Madison, WI, 53706

* Corresponding author (contact: toomarian@wisc.edu) 


\begin{abstract}
Mapping numbers onto space is a common cognitive representation that has been explored in both behavioral and neuroimaging contexts. Empirical work probing the diverse nature of these spatial-numerical associations (SNAs) has led researchers to question 1) how the human brain links numbers with space, and 2) whether this link is biologically vs. culturally determined. We review the existing literature on the development of SNAs and situate that empirical work within cognitive and neuroscientific theoretical frameworks. We propose that an evolutionarily-ancient frontal-parietal circuit broadly tuned to multiple magnitude dimensions provides the phylogenetic substrate for SNAs, while enculturation and sensorimotor experience shape their specific profiles. We then use this perspective to discuss educational implications and highlight promising avenues for future research.
\end{abstract}

Keywords:

spatial-numerical association; SNARC; mental number line; numerical cognition; spatial cognition; ATOM; neuronal recycling; educational neuroscience; developmental cognitive neuroscience 


\section{On the Genesis of Spatial-Numerical Associations: Evolutionary and Cultural Factors Co-Construct the Mental Number Line}

\section{Introduction}

The link between numbers and space is evident in a wide range of mathematical contexts. From early finger counting and basic measurement tools, to the Cartesian coordinate system and complex geometric proofs, our conceptualization of numerical magnitude is deeply spatial (Dehaene, 1997). Despite differences in how these associations manifest, the spatial mapping of numbers is a universal cognitive strategy that has been explored in both behavioral and neuroimaging contexts. The recent increase in empirical work probing the nature of these spatialnumerical associations (SNAs) leads to several pertinent questions: Why does the human brain link numbers with space? To what extent are SNAs biologically determined vs. culturally mediated? How can broad theories of developmental cognitive neuroscience (DCN) be integrated with theories of numerical and spatial development? What factors determine individual differences in the strength of these SNAs, and what are the implications for learning about math and numbers? These questions have traditionally been addressed either from a "nature" or "nurture" approach; we argue for a more integrated view of these questions. To demonstrate the strengths of such an approach, we present a critical review of the existing literature on SNAs with a focus on development, to produce the first comprehensive review of the developmental cognitive neuroscience of spatial-numerical associations.

This review is critical to a principled discussion of how spatial-numerical associations may be leveraged to improve instructional approaches. To this end, we first detail the behavioral nature of these associations, with a specific focus on the extent to which SNAs are the result of a pre-specified, intrinsic mapping vs. shaped through experience. Second, we describe the 
cognitive and neural basis for these associations. We will then situate this body of empirical work within cognitive and neuroscientific theoretical frameworks. Finally, we explicitly address how both DCN theories and numerical and spatial development theories converge and allow for spatial-numerical associations to be influenced over the course of development. We conclude the review with a brief discussion of relevant training studies and their implications, along with identifying promising avenues for future educational neuroscience research on numbers and space.

\subsection{Spatial-Numerical Associations}

A wide range of behavioral paradigms have documented a mental association between numerical magnitudes and space. In a seminal study by Dehaene and colleagues (1993), participants were asked to classify a number as either odd or even, a task unrelated to the magnitude of the numbers they were processing. Participants were consistently faster to make their responses on the right for larger numbers and on the left for smaller numbers, suggesting subconscious activation of a mental representation of numerical magnitude. This Spatial Numerical Association of Response Codes (SNARC effect) has proven to be quite robust (Hubbard et al., 2005; Wood et al., 2008): the effect emerges regardless of dominant hand (Dehaene et al., 1993), when hands are crossed (Dehaene et al., 1993; but see Wood et al., 2006), with foot pedal responses (Schwarz and Müller, 2006), across modalities (Nuerk et al., 2005;

Schwarz and Keus, 2004), when cued implicitly (e.g. Fischer et al., 2003), in early-blind individuals (Crollen et al., 2013), and even when participants are tested on the phonemic content of number words (Fias et al., 1996). The effect is also flexible and can be shaped by task constraints (Georges et al., 2014; Li et al., 2016). 
While the SNARC is the most oft-cited metric of spatial-numerical associations in cognition, it is important to note that phenomena other than the classic SNARC demonstrate the widespread influence of SNAs on cognition. For example, the implicit association between numbers and sides of space can induce covert attentional shifts, with attention orienting to the left or right following small or large cues, respectively (Dodd et al., 2008; Fischer et al., 2003; Galfano et al., 2006; Goffaux et al., 2012; Nicholls et al., 2008; Ranzini et al., 2009; Ristic and Kingstone, 2006; Salillas et al., 2008; Schuller et al., 2014; Schwarz and Keus, 2004). This finding has been called the attentional-SNARC (Att-SNARC). In the original experiment (Fischer et al., 2003), participants were instructed to respond to a target stimulus on either the left or right side of the screen. When these targets were preceded by an irrelevant numerical digit, participants were faster to respond to left-side targets when preceded by digits with relatively smaller numerical magnitude, and to right-side targets when preceded by larger magnitudes. While this effect has been replicated numerous times, there have also been a number of failed replications (e.g. Fattorini et al., 2015; Zanolie and Pecher, 2014). As a result of these contradictory results, the Att-SNARC is currently the subject of a massive Registered Replication effort (Colling and Holcombe, 2017).

Other paradigms that have demonstrated links between numbers and space include number-to-position/number line estimation tasks (e.g., Berteletti et al., 2010); studies of patients with hemispatial neglect (e.g. Zorzi et al., 2002; see section 3.2); number line bisection tasks (e.g. Calabria and Rossetti, 2005); attention biased in auditory space (e.g. Mitchell et al., 2012); grayscale tasks (e.g. Nicholls et al., 2008); and nonsymbolic numerosity tasks such as those used by non-human primates (e.g. Gazes et al., 2017; Rugani et al., 2015; see section 2.2.1). Each paradigm offers a unique advantage or perspective from the others. For instance, the grayscale 
task employed by Nicholls et al. (2008) avoided the necessity for any lateralized responses, asking participants to verbally judge the relative magnitude of numbers and select the darker of two vertically-arranged grayscales. They found evidence of spatial congruency, such that smaller numbers were associated with the left and larger numbers with the right, even in the absence of lateralized responses.

These demonstrated associations between numerical magnitude and sides of space have led researchers to hypothesize the existence of a mental number line (MNL). This internal, spatially organized linear continuum extends horizontally, with larger numerical magnitudes typically located incrementally to the right on the line-- though as will be discussed in section 2.2, the orientation of the MNL appears to be culturally determined. Representations on the MNL are dynamic and flexible based on boundaries and task requirements (Dehaene et al., 1993). People are consistently faster and more accurate to distinguish between numbers that are more distant than those that are closer together, a phenomenon known as the distance effect (Dehaene et al., 1990; Moyer and Landauer, 1967). This is taken as a reflection of a linear, analog mental representation of number (Restle, 1970; but see section 2.2.4 for a discussion of alternative accounts). Greater representational overlap between close numbers results in less accurate and slower comparisons than when comparing more distant number pairs. We note, however, that while the distance effect provides support for the mental number line hypothesis, it is not necessarily evidence of a spatial association with numerical magnitude. Indeed, comparison of event related potentials (ERP) during numerical comparison (Dehaene, 1996) and numerical cuing paradigms (Ranzini et al., 2009) suggest that comparison is associated with modulations of an early component (200 ms after stimulus onset) while spatial mappings are associated with later ERP components (300-500 ms after stimulus onset). Thus, numerical 
comparison and spatial mappings likely depend on separate stages of processing, with comparison occurring prior to spatial mappings (discussed in greater depth in section 3.3). We contend that the distance effect, despite its name, is an index of magnitude processing rather than SNAs, per se. Thus, in this review, we focus primarily on the SNARC and related effects as indices of spatial magnitude processing.

One additional issue is whether the SNARC depends on cardinal or ordinal numerical information. Cardinality refers to the total number of items in a set and is tied to concept of numerical magnitude, whereas ordinality refers to numerical sequencing and is relative in nature. This was first investigated by Gevers et al. (2003) by testing for the presence of SNARC-like effects with non-numerical ordered sequences (letters and months), in which they found evidence of spatial coding. Subsequent studies have replicated and extended these findings (Di Bono and Zorzi, 2013; Gevers et al., 2004) However, other studies suggest spatial coding is specific to numbers, not ordered sequences more broadly (e.g. Zorzi et al., 2006). For instance, in an investigation of the Att-SNARC paradigm with both numbers and non-numerical sequences (letters, days, months), the Att-SNARC only reliably emerged for numbers, or when order was relevant to the non-numerical stimulus (e.g. "Is the letter shown before or after 'K'?") (Dodd et al., 2008). Interestingly, a recent within-subjects investigation showed a dissociation between cardinal and ordinal SNARC effects, suggesting that these effects rely on separate cognitive mechanisms (Schroeder et al., 2017). Thus, while the ordinality/cardinality distinction is an important one, we focus here primarily on cardinality as it relates to numerical magnitude, with additional mentions of ordinality where appropriate.

\section{Building an SNA: Innate Prespecification or Cultural Acquisition?}


Historically, SNAs have often been viewed from a "nature" or "nurture" theoretical standpoint. Innate prespecification theories have typically focused on findings from preverbal infants and non-human animals to demonstrate that SNAs are universal and occur even without specific cultural influences. Conversely, cultural acquisition theories have focused on findings that the direction of SNAs varies across cultures, and that there is a long developmental process of acquiring such SNAs, which may also involve other culturally mediated acquisitions such as finger counting. Before discussing the cognitive and neural theories that inform this debate, we first review behavioral evidence that has typically been taken as support for either a strong innate or cultural view.

\subsection{Innate Prespecification}

\subsubsection{Evidence from Infants and Preliterate Children}

If the SNARC effect is indeed the result of an innate mechanism that privileges the link between numbers and space, there should be evidence of it from a young age, before infants have been introduced to cultural activities, such as reading or writing. Thus, studies of humans in the period prior to formal schooling are crucial for building an understanding of the origin of SNAs (for a review, see McCrink and Opfer, 2014). Such studies reduce the influence of explicit instruction and experience with classroom number lines as possible sources or reinforcements of a defined link between numbers and space. To test for spatial-numerical preferences in infants, researchers typically employ non-symbolic representations of quantity (controlled for other psychophysical properties). One study using non-symbolic numerosity arrays and line lengths found that 8 month old American infants associate an increasing series of numerosity arrays to an increasing series of line lengths (de Hevia and Spelke, 2010; Experiment 1). The same group found that at 7 months, infants show a preference for numerical sequences of dot arrays and line 
lengths that increase in the rightward direction, rather than the leftward direction (de Hevia et al., 2014a). These studies by de Hevia and colleagues will be discussed further in section 4.2 in the context of general magnitude processing, but provide important early evidence of SNAs in infants.

There is also recent evidence showing that infants as young as 8-9 months orient their visual attention in response to task-irrelevant numerical cues (Bulf et al., 2016). This study was an adapted version of the classic Att-SNARC paradigm used to test for endogenous shifts of attention in adults (Fischer et al., 2003; Posner, 1980). Similarly, Bulf et al. found that infants were faster to orient their attention to targets on the side of space congruent with the relative size of a previously presented non-symbolic numerical display (either dots or a shape). These studies with preverbal infants provide evidence for an early sensitivity to ordinality and increasing magnitudes, and support accounts of SNA development that propose an innate predisposition to map numerosities to sides of space.

However, there is a key limitation to this conclusion. Crucially, these studies were all conducted in American infants, and demonstrated a bias toward the culturally-appropriate direction. While hemispheric lateralization has been argued as one source for this preferential mapping, it is also possible that in just seven months of life, these infants picked up environmental cues leading to their preference. For example, by age 4, preliterate preschoolers already show evidence of a culturally congruent SNA (Patro and Haman, 2012; see also Tversky et al., 1991). Thus, in order to definitively state that the results point to an innately-determined preference, future studies should be conducted with preverbal infants raised in a culture with a predominantly right-to-left reading and writing direction, such as Arabic-speaking populations. If these infants also demonstrate a preference for left-to-right increasing numerosities and line- 
length mappings, which would be incongruent with cultural cues, this would provide more definitive evidence for an innate mapping uninfluenced by environmental cues.

\subsubsection{Spatial-Numerical Associations in Other Species}

While preverbal infants are the key population of interest for elucidating the impact of cultural experience on shaping SNAs, animal studies can address larger questions of the possible evolutionary nature of these associations. Humans are the only species with formal, culturallytransmitted reading and writing systems, which may differentially affect the nature of mental associations we form. Exploring whether other species also show evidence of a mental number line, or at least a preference for spatial orientations, is crucial for understanding how and why SNAs emerge in humans.

Evidence from animal studies of birds and monkeys has bolstered the argument that there is an evolutionary or biological basis for spatial-numeric associations that arises prior to and independent of experience. Chicks less than a week old and adult nutcrackers both demonstrate a leftward bias in an ordinal rotation task (Rugani et al., 2010). After being trained to identify the fourth or sixth item in a vertically-oriented display, both groups were more likely to select the fourth or sixth item from the left once the display was shown in a horizontal orientation during the test condition, suggesting an inherent leftward spatial bias in birds. A later study by the same group further demonstrated that chicks associate smaller numerosities with the left and larger numerosities with the right (Rugani et al., 2015). In a series of three experiments, chicks consistently preferred the panel on the left when shown displays with fewer elements, and chose the panel on the right for more numerous displays. The authors conclude that this is the first evidence of a MNL in untrained, inexperienced animals. 
Despite the tantalizing evidence that such comparative studies of SNAs/the MNL provide, it is important to consider the limitations of the claims made by the authors of these studies. Rugani et al. (2015) produce compelling evidence for a categorical mapping between numbers and sides of space. However, as Nunez and Fias (2015) argue, the results demonstrate, at best, an association but not a true mapping, since there is no evidence of a linear distance effect or a real baseline understanding of chick behavior. They argue that chicks may not even be an appropriate animal model for studying human spatial cognition due to their lack of a corpus callosum, which might magnify hemispheric differences/lateralization (for a reply to these objections, see Rugani et al., 2015; Shaki and Fischer, 2015).

In a study with rhesus macaques (Drucker and Brannon, 2014), the ordinal rotation paradigm used by Rugani et al. (2010) revealed a left-to-right oriented SNA in monkeys as well. Importantly, a number of the issues that arose with the study of chicks are not applicable in this context (e.g. there is no evidence of a side or handedness bias in monkeys, and the primate brains are less lateralized than birds' brains). Furthermore, chimps who were trained to sequence singledigit Arabic numerals when randomly spaced on a screen were later faster to respond during a test to small digits on the left and large digits on the right (Adachi, 2014). Despite the fact that ordinality was explicitly taught, the chimps received no explicit, directional training, and yet a left-to-right order was spontaneously preferred. One possible explanation for this leftward bias is the right hemisphere dominance for visuospatial tasks (Vallortigara and Rogers, 2005). These studies demonstrate that there is reason to believe that SNAs are at least partially biologically determined.

Crucially, not all studies of non-human primates have provided such strong support for an innate and consistent SNA. A recent study found spatial mappings of number in orangutans and 
gorillas, but also demonstrated notable inter-individual variability, as well as flexibility in spatial orientations following reversal of task instructions (Gazes et al., 2017). This pattern of results demonstrates not only that non-human primates can and do represent numerical concepts spatially, but that these representations are flexible and presumably influenced by external factors. Although these data support the view that SNAs have deep evolutionary foundations (see also Haun et al., 2011), it is clear that biological factors cannot fully account for the development of SNAs.

\subsection{Cultural Acquisition}

\subsubsection{Cross-Cultural Differences}

While SNAs appear quite robustly across various tasks and populations, there is significant variation in the direction of these associations across cultures (for a review, see Göbel et al., 2011). In the original set of studies describing the classic left-right SNARC in French speaking participants, Dehaene et al. (1993) also describe a null effect in a group of Iranian subjects, who read and write Farsi from right-to-left but have bidirectional numerical structures (for similar results in: Hebrew speakers, see Shaki et al., 2009; Arabic-English biliterates, see Zebian, 2005). Notably, the strength of the left-to-right SNARC increased in individuals who had spent increasing amounts of time in France, suggesting that increased exposure to left-to-right ordered activities reshapes SNAs. Different linguistic notations of numerical stimuli can even shape spatial associations within the same individual. Chinese readers exhibit a left-to-right SNA for Arabic numerals, but a top-to-bottom SNA for Chinese number words, congruent with the directionality for each notation (Hung et al., 2008).

The prevailing explanation for these differences is the strong influence of directional cultural activities, such as reading, writing and counting direction (Nuerk et al., 2015). Indeed, 
this account receives support from studies such as Zebian's (2005) study of Arabic-speaking illiterates, who showed no evidence of a directional SNARC. Some also suggest that linguistic factors (e.g. Imbo et al., 2012) or finger counting can account for the mapping of SNAs. A recent cross-cultural study of parent-child interactions during a spatial task showed that parents modeled behaviors for their child in a culturally-consistent manner, highlighting parent interaction as a likely avenue for early spatial biases (McCrink et al., 2017). In order to explicitly test these theories of spatial-numerical development, studies of SNAs prior to language development and in those with limited or varied cultural experience are necessary.

In addition to informing questions of SNA directionality, cross-cultural studies have also challenged the existence and form of these mappings. Dehaene et al. (2008) investigated numerical representations in the Mundurucu, a remote, indigenous group in Brazil with little access to formal education and a restricted number vocabulary. The Mundurucu appeared to employ a logarithmic mapping for both symbolic and nonsymbolic numbers, whereas Western individuals represent symbolic numbers linearly. The authors interpret this as evidence for 1) a universal tendency to link numbers and space, 2) an early intuition to represent numbers logarithmically, and 3) a shift to linear representations as a consequence of formal education (though this interpretation has since been challenged e.g., Cantlon et al., 2009; Núñez, 2011). Similar investigations with the Yupno in Papua New Guinea, who have received little-to-no formal schooling, have shown that they do indeed map numbers to space but in a categorical fashion (i.e., they place numbers on the respective endpoints in a number line task)(Núñez et al., 2012). The extent of this categorical mapping varied as a function of experience with formal school environments. These findings, along with more recent work on linear ordering in the same population (Cooperrider et al., 2017), have been taken as evidence that extensive cultural 
experience is required to regiment/reinforce a specific mapping type. In contrast to Western participants who consistently rely on linear ordering, the Yupno have limited exposure to this principle, and thus more readily employ categorical mappings (Cooperrider et al., 2017). Such investigations with remote populations are valuable for deepening our understanding of how cultural norms likely reinforce SNA strength, type, and directionality.

\subsubsection{Development of Spatial-Numerical Associations}

Since the initial discovery of behavioral SNAs in adults by Dehaene and colleagues (1993), the question of how and when these associations develop has been addressed by many researchers using a variety of methods, including behavioral and neuroimaging studies of infants, typically developing children, nonhuman primates and young animals of other species (e.g. baby chicks). Understanding the developmental trajectory and species specificity of spatial mappings of numerical magnitude will aid in elucidating their underlying mechanism.

Several studies have investigated spatial-numerical associations in literate schoolchildren using classic SNARC paradigms and number line estimation tasks but have yielded inconsistent results. The first developmental study of the SNARC used a parity task to successfully demonstrate the emergence of the effect as early as age 9 , but it was notably absent at age 7 -- the youngest age group in the study (Berch et al., 1999). Interestingly, these effects appeared to attenuate with increasing age, with a SNARC only emerging for "odd" responses in 11-13 year olds. It is possible that these effects may have been modulated by differing strategies for classifying the parity of presented digits, or a developing understanding of parity more generally.

Later studies attempted to disambiguate these findings with slight task manipulations and additions. For instance, van Galen \& Reitsma (2008) found that the SNARC emerged at 7 years for a magnitude relevant task, but at 9 years for an attentional, non-magnitude-relevant task. A 
distance effect was present across all the tested age ranges, including adults. These findings have been bolstered by a more recent developmental study that found SNARC effects in 7- and 8year-olds, but not at age 6, despite significant distance effects at all age groups (Gibson and Maurer, 2016). White, Szucs, \& Soltesz (2012) also found that magnitude-relevant SNARC effects emerged a year earlier than a SNARC based on a parity judgment. These studies suggest that while even young children likely represent numbers on a mental number line, more implicit, automatic representations are strengthened with age.

Results from a study of kindergarteners by Hoffmann et al. (2013) have challenged these results by employing a color discrimination task, returning to the "magnitude-irrelevant" nature of the parity judgment task. A sample of 5-6 year olds completed both the classic magnitudejudgement SNARC task (i.e., indicated whether the number was larger or smaller than 5) and a color-judgement task (i.e., indicated whether the number was red or green), with the order of tasks counterbalanced. They found evidence of group-level SNARC effects in response to the color-discrimination task, but not the numerical magnitude comparison task. The authors suggest that the SNARC may have indeed been present in younger age groups of other studies but did not appear due to the explicit nature of the task. It is worth noting, however, that these results were subject to order effects, such that only the group who did the color task after the magnitude task exhibited a SNARC, inviting the possibility that priming effects may have driven these results. The absence of a SNARC for magnitude relevant tasks in young children has received additional support from Chan and Wong (2016), who showed that kindergarteners exhibit a leftright spatial bias in response to ordinal but not magnitude information.

The pattern of results for distance and SNARC effects from all of the studies discussed above may imply that access to numerical magnitude (as measured by the distance effect) may 
be dissociated from spatial representations (measured by the SNARC). These studies also imply a dynamic developmental trajectory for linking ordinality and cardinality, as well as for attending to other properties of number such as parity. Although there has been a recent effort to construct a taxonomy for SNA development (Patro et al., 2014), it appears that ultimately, there is little consensus as to what exactly this developmental trajectory looks like, particularly in the schoolage years (Georges et al., 2017; Gibson and Maurer, 2016; Schneider et al., 2009). Rather, these studies highlight that the development of SNAs in schoolchildren is variable and complex, and likely the result of interacting intrinsic and extrinsic factors. A stronger understanding of how children begin to structure their spatial-numerical mental associations is crucial both from a theoretical perspective and for informing pedagogical techniques.

\subsubsection{The Role of Visuomotor Skills}

A leading hypothesis for the development of SNAs is that learned skills, specifically reading and finger-counting, play a key role in determining the profile of SNAs across individuals and cultural populations. Both activities, addressed by the "common reading account" of SNA development, are modeled from a young age and are generally consistent over time and by geographical region (Nuerk et al., 2015). Though children do not formally learn to read for the first few years of life, subtle cues from their surroundings (e.g. watching an adult scan the page of a magazine, or playing early counting games and activities), may lay the cognitive foundation for SNAs to later emerge. Recent evidence from cross-sectional studies of SNAs across the lifespan have lent additional support for this hypothesis (Hoffmann et al., 2014; Ninaus et al., 2017). SNAs are not only present across all age groups but appear to strengthen with age (Wood et al., 2008), suggesting that prolonged exposure to environmental cues may reinforce these associations. 
Finger-counting habits were first linked to the profile of the SNARC in a study by Fischer (2008), in which participants were classified as either "left-starters" or "right-starters" depending on the hand they chose to start with when counting to ten. Somewhat surprisingly, a majority of Scottish English speakers started counting on the left, regardless of hand dominance, which would be congruent with the direction of their SNARC and reading direction. Additionally, left-starters exhibited stronger individual SNARC effects, providing support for the “manumerical cognition” hypothesis of SNA development (see also Fischer and Brugger, 2011). This account even appears to hold up in cross-cultural comparisons. Lindemann et al. (2011) showed that Western subjects more likely to start counting on the thumb on their left hand and Middle-Easterners more likely to start counting with the pinky finger of their right hand, consistent with direction of the MNL discussed in other cross-cultural research (e.g. Shaki et al., 2009).

These surprising results have one critical limitation- with the exception of one study (Riello and Rusconi, 2011), the data on finger counting was collected by asking participants to imagine counting on their fingers, and then write the numbers next to a diagram of a pair of hands (or enter values on the computer version, as in Lindemann et al., 2011). This method of finger counting may not actually be representative of an implicit association between fingers and numerical magnitudes, but rather, just a recapitulation of an SNA formed by the MNL. That is, by asking participants to first imagine how they would count on their fingers rather than simply asking them to count out loud and recording their responses, it is impossible to disentangle the contribution of their internal SNA from their true, body-based finger counting habit. In support of this possibility, Brozzoli et al. (2008) found that when spatial and finger representations were placed in competition in a numerical touch perception paradigm, spatial representations 
dominated. Specifically, when participants' right hands were face down, they responded faster to a tactile stimulus on the pinky/little finger after presentation of a large number relative to presentation of a small number, a pattern that was reversed when participants' palms faced upward. These results reflect dominance of an extrapersonal spatial mapping over a body-based mapping, highlighting the possible confound present in current finger-counting studies.

As it is likely that finger counting is just one of the many contributors to the formation and direction of SNAs, it is helpful to understand the degree to which finger counting influences SNAs in individuals. Fabbri \& Guarini (2016) found that finger counting habits impacted performance on an implicit numerical task (digit-string bisection) but not an explicit numerical task (number-to-position). Furthermore, several studies have shown the SNARC to be malleable and dependent on task demands and characteristics (Bächtold et al., 1998; Fischer et al., 2010; Hung et al., 2008; Pfister et al., 2013; Shaki and Fischer, 2008). One study demonstrated that training for approximately fifteen minutes on a certain direction of finger counting, either congruent or incongruent with reading direction, impacted the presence and direction of the resulting SNARC effect (Pitt and Casasanto, 2014). Specifically, training American participants to count on their fingers from right-to-left reversed the SNARC in a significant number of participants, thereby extinguishing the overall group-level SNARC. This malleability supports the view that SNARC effects are not wholly intrinsic and specified early in development, but rather that experience molds SNAs into forms befitting of the local environment and task demands.

\subsubsection{The Working Memory Account}

Contrary to the "common reading" and "manumerical cognition" theories of SNA development is the working memory (WM) account, which proposes that links between numbers 
and space emerge as a result of temporary position coding in working memory, rather than as a result of more stable, long-term associations (Abrahamse et al., 2016; Fias and Dijck, 2016; van Dijck and Fias, 2011). Specifically, items in an ordered sequence are hypothesized to be indexed in WM during task execution; this positional coding then results in SNARC effects that reflect specific task constraints. There is now substantial evidence in support of this view (Aiello et al., 2013; Fias et al., 2011; Herrera et al., 2008; Rotondaro et al., 2015; Santens and Gevers, 2008; van Dijck et al., 2012, 2011; van Dijck and Fias, 2011). For example, the SNARC effect appears to be diminished during a simultaneous visuospatial—but not phonological—WM task, while the distance effect is unaffected by dual-task WM demands (Herrera et al., 2008).

The WM account has recently been challenged by Cheung and Lourenco (2016), who employed order judgement tasks for both number and letter pairs. Pairs were shown in either "ascending" (earlier-to-later in the ordinal sequence) or "descending" (later-to-earlier in the ordinal sequence) conditions. Their finding that ascending numbers - but not letters - were associated with the right side of space and descending with the left is consistent with the MNL model and not WM model. Several other recent accounts have demonstrated that the ordinal position effect and SNARC effect are not mutually exclusive, thus supporting both models (Ginsburg and Gevers, 2015; Huber et al., 2016). Taken together, these accounts are in line with our view that multiple influences contribute to the pattern and profile of SNARC effects.

\subsubsection{The Verbal Coding Account}

In yet another account of number-space links, some argue that SNARC effects are the result of verbal tags or coding. One such case is polarity correspondence (Proctor and Cho, 2006), in which left is associated with small/odd (negative poles) and right associated with large/even (positive poles). While this account has received some support (Landy et al., 2008; 
Proctor and Xiong, 2015; Santens and Gevers, 2008), the polarity correspondence principle has generally been ruled out as the underlying mechanism for the SNARC (Bonato et al., 2012; Di Rosa et al., 2017; Dollman and Levine, 2016; Leth-Steensen and Citta, 2016; Santiago and Lakens, 2015; Shaki et al., 2012), mostly due to evidence from modulators of the SNARC effect such as reading habits or cross-cultural factors.

This associative account is related to the measurable phenomenon of the MARC effect (Markedness Association of Response Codes), in which there is a linguistic association between numerical words and "odd" or "even," resulting in a parity by response side interaction (Berch et al., 1999; Nuerk et al., 2004). Berch et al. (1999) found evidence of a MARC effect for children in Grades 6 and 8, but not for younger children in Grades 2-4, suggesting increasing dominance of linguistic factors with increasing age. However, the trajectory and relative contributions of verbal and spatial coding of number is still under debate. Imbo et al. (2012) tested the hypothesis that children initially associate numbers with space because they are surrounded by number lines, rulers, etc. in setting such as classrooms and subsequently develop verbal recoding of magnitudes (e.g. associating small numbers with the word "left" rather than the left side of space). However, their results revealed that verbal associations were in fact stronger than spatial associations in developing children (9- and 11-year olds), lending support to the claim that early verbal associations subsequently influence spatial coding (see also Gevers et al., 2010). Ultimately, verbal and visuospatial cues may both act as additional external cues to reinforce internal spatial representations of number, though the exact profile of these influences is yet unknown. Crucially, SNAs appear to emerge prior to the earliest evidence of a MARC, including in children who have yet to master even/odd or left/right distinctions (Berch et al., 1999; van Galen and Reitsma, 2008). Taken together with the evidence that verbal codes do indeed play a 
role in SNAs in older children, we suggest that verbal codes serve to reinforce spatial associations, rather than induce them. Indeed, the strength of the verbal code relative to spatial associations is neither surprising (given the crucial role of language in knowledge construction) nor damaging to other accounts of SNA development. Rather, in our view, the verbal coding account is parsimonious with both the manumerical cognition and common reading accounts, in that they all suggest that cultural factors influence the way we conceptualize the relationship between numbers and space and play a part in a multi-faceted, complex development of SNAs-though the existence of such associations may be supported by prespecified mechanisms.

A wide array of behavioral studies has provided compelling evidence for ontogenetic specification of SNAs, but also demonstrates flexibility and modification due to cultural environment. With these complementary mechanisms in mind, we now turn to the underlying neural mechanisms for supporting evidence of a phylogenetically ancient, ontogenetically early capacity for integrating space and number.

\section{Neural Underpinnings of Space and Number}

\subsection{Distributed Processing of SNAs}

Spatial and numerical processing both rely on a network of frontoparietal regions in the brain. Converging evidence from patient studies, monkey homologues, and extensive neuroimaging in humans has demonstrated a representational overlap between numbers and space specifically in parietal cortex (e.g. Hubbard et al., 2009, 2005; Knops et al., 2009), with particular attention paid to the intraparietal sulcus (IPS) in the posterior parietal cortex (PPC). However, in the quest to make sense of the complex pattern of findings regarding the nature of number-space associations, it has become increasingly clear that the neural circuitry underlying SNAs is not restricted to parietal regions. Rather, as we will demonstrate in this section, there is 
increasing evidence of more distributed processing of SNAs across frontoparietal networks.

Here, we discuss some of these recent advances in our understanding of the neural relationship between numbers and space, with a focus on how both frontal and parietal regions_-particularly IPS/PPC — contribute to number-space associations.

\subsection{Evidence from Neuropsychological Studies}

Neuropsychological studies of patients with parietal injuries have long suggested a link between numbers and space. For example, Gerstmann's Syndrome includes a classic tetrad of symptoms including deficits in numerical and spatial skills: acalculia, left-right confusion, finger agnosia and dysgraphia (difficulties with writing)(Benton, 1992; Gerstmann, 1940). Mayer et al. (1999) identified a case of pure Gerstmann's syndrome due to a small lesion in the white matter beneath the left angular gyrus. After substantial testing of all the elements of Gerstmann's syndrome, the authors suggested that the common deficit linking the symptoms in this patient was a deficit in visuospatial manipulations, which is consistent with our hypothesis of numerical-spatial interaction in the parietal lobe. Interpretation of symptom-association data remains complicated because it could be due to the mere anatomical proximity of functionallydistinct systems. Indeed, Rusconi et al. (2009) performed high-resolution fMRI to map the cortical regions involved in Gerstmann's syndrome and found that nearby parietal regions are involved in tasks related to the Gerstmann's tetrad. Although no single cortical region was implicated for the four tasks, DTI tractography from these functional regions indicated a small white matter pathway_consistent with the location of the white matter lesion in Mayer et al. (1999) — that may be the common locus of injury in Gerstmann's.

Although previous studies have broadly implicated parietal cortex in numerical and spatial processing, the first causal evidence for the specific role of PPC in SNAs comes from 
studies of patients with hemispatial neglect (e.g. Zorzi et al., 2002), as well as healthy patients using the same methodology to study pseudoneglect (Umiltà et al., 2009). Patients with right parietal brain lesions will neglect stimuli presented to the contralateral (left side), and thus often skew to the right when asked to mark the middle of a physical line (a standard line bisection task). Zorzi et al. (2002) demonstrated that these patients showed a similar rightward bias when asked to verbally report the middle number in a given range (e.g. erroneously reporting that 14 was the midpoint between 11 and 15), despite their ability to do calculations and compare numerical magnitudes well. Repetitive transcranial magnetic stimulation (rTMS) administered to healthy participants (i.e. those without brain damage) has corroborated these findings. Specifically, rTMS to PPC led to neglect-like results on a number-line bisection task, while inhibition of occipital areas did not (Göbel et al., 2006). These early results highlighted the highly spatial nature of the putative MNL as well as the striking similarity of the MNL-a mental representation - to a physical line.

However, there have been several critiques of this early account of the link between spatial neglect and number line bisection. For instance, Doricchi et al. (2005) showed that individuals with known brain damage who demonstrated lateral deviation on a number-interval bisection task had lesions in prefrontal brain regions and impairments in spatial working memory, while neglect patients without lateral number-interval deviation had no prefrontal lesions. While impairment in spatial working memory for those with neglect on the MNL can be seen as support for the WM account of SNAs (discussed in 2.2.4), spatial WM and spatial attention are known to overlap quite significantly at both the behavioral (e.g. Awh and Jonides, 2001) and neural (Ikkai and Curtis, 2011; Silk et al., 2010) levels. A case study by van Dijck et al. (2011) bolsters the case for WM involvement in spatial-numerical representations. Their 
patient with left hemisphere-damage demonstrated right-side neglect on a variety of representational tasks and in physical space, but left-side neglect on tasks recruiting the MNL (number-interval bisection). In addition to finding that the patient had impaired verbal WM span, they attributed this discrepancy to difficulty with verbal sequences represented spatially (see also Aiello et al., 2013, 2012 for accounts of neglect not attributed to representational space). These findings highlight an important dissociation between perceptual and representational neglect (see also Coslett, 1997; Guariglia et al., 2013; Priftis et al., 2006; Rotondaro et al., 2015; Wansard et al., 2016) and provide initial support for distributed neural processing of SNAs.

More research on perceptual and representational neglect has the potential to further disambiguate the role of various networks subserving the MNL. To date, most studies have focused only on associations and dissociations between number line and physical line bisection, based on the apparent task similarities. However, we argue that a closer examination of the task demands suggest that deficits in physical line bisection would be observed with perceptual neglect, whereas deficits in number line bisection should be observed only in cases of representational neglect. In the majority of cases where perceptual and representational neglect co-occur, we would predict an association between physical and mental number line bisection; in cases where they dissociate, we would we predict similar dissociations between physical line bisection and mental number line bisection. To our knowledge, no study has systematically investigated these four phenomena in the same patients to establish whether and how perceptual and representational neglect relate to mental number line bisection.

\subsection{Neural Overlap in Parietal Regions}

In a classic, early investigation of the neural locus of SNAs, Fias et al. (2001) hypothesized that common processing mechanisms in parietal cortex create a "neural overlap" 
for spatial orientation and numerical magnitude. To test this, they disambiguated the importance of various features of numerical comparison, specifically number orientation, color, and shape, by measuring differences in response time based on responses to these features, much like a parity task (see also Lammertyn et al., 2002). For example, in one color variant, participants responded to whether the number was presented in red or green; in the orientation variant, responses were based on seeing either a horizontal or vertical line superimposed on the number. Even though numerical magnitude was irrelevant to task performance, a SNARC effect only emerged for orientation judgments (processed by the dorsal visual stream, like number), but not for color or shape (processed in the ventral stream) (but see Hoffmann et al., 2013 for evidence of a color-discrimination SNARC in children). Mitchell et al. (2012) extended these results cross-modally to auditory stimuli, demonstrating a SNARC for orientation but not color judgements of an onscreen stimulus following auditory number words.

Despite this empirical support for the neural overlap account, this line of reasoning has been challenged on several fronts. For example, the observation that dorsal-stream regions are involved in color processing — specifically in anterior and middle IPS — suggests that number and color processing might overlap, contrary to the neural overlap account (Claeys et al., 2004). Additionally, Hoffmann et al. (2013) successfully elicited a SNARC effect based on color judgements of numerical stimuli in a sample of young children, which would potentially be implausible by the neural overlap account. Note, however, that one explanation for this finding might be the possibility of more widespread color-processing pathways in children compared to adults, leading to greater neural overlap between number and color processing. Lastly, if the SNARC effect is related to response selection (e.g. Keus et al., 2005) rather than stimulus properties (e.g. as proposed by Mapelli et al., 2003), the neural overlap cannot hold. We argue, 
however, that given the functional dissociations between anterior IPS (aIPS) and posterior IPS (pIPS), with pIPS activation modulated by spatial position of numbers (e.g. Kanayet et al., in press), the neural overlap account is not invalidated by discoveries such as color processing in parietal regions. Rather, testing this theory simply requires an investigation with higher resolution. For example, a functional magnetic resonance imaging (fMRI) study using color and orientation SNARC tasks, focused on disentangling involvement of IPS subregions, may help to further elucidate the extent of representational overlap between various features of numerical processing. Furthermore, whether the SNARC emerges as a result of semantics/stimulus properties or response selection is still an open debate, with recent evidence suggesting that the SNARC varies as a result of both factors and cannot be considered a unitary phenomenon (Basso Moro et al., 2017; see also Koten et al., 2011). Ultimately, the neural overlap account has provided a useful starting point for investigations of neural underpinnings of SNAs, but recent investigations can and should move beyond this account.

\subsection{Spatial-Numerical Processing in Parietal Cortex}

There have been independent literatures on both numerical (e.g. Dehaene et al., 2003; Piazza et al., 2007) and spatial processing (e.g. Silk et al., 2010) that have each separately implicated parietal regions. However, until recently, few studies have directly investigated the neural systems that support the links between numbers and space. Studies that directly investigate numerical and spatial processing simultaneously can offer more reliable evidence of shared neural representations between numbers and space. However, there is currently a dearth of neuroimaging studies that specifically investigate number-space mappings, as it has only been in the past decade that such studies have been conducted. 
In one such study, Knops et al. (2009) tested the hypothesis that cortical circuits for spatial attention are related to mental arithmetic by training a multivariate classifier on directional eye movements. They found that regions of PPC and frontal eye fields (FEF) involved in saccadic eye movements were also recruited during mental arithmetic of both symbolic and non-symbolic numerosities, suggesting that mental representations of magnitudes involves shifting attention in space. Notably, despite this functional overlap, the multivariate classifier used in the study only significantly decoded arithmetic operations in PPC, not FEF. While it's possible that the smaller size of FEF relative to the posterior superior parietal lobule (PSPL) could account for this, it also suggests that calculation specifically recruits parietal rather than frontal spatial mechanisms. Indeed, a recent fMRI study (Mathieu et al., 2017) has shown that even the mere presentation of arithmetic operators leads to increased activation within spatial regions (PSPL and FEF), consistent with the more specific role suggested by Knops et al (2009).

Cutini et al. (2014) used functional near-infrared spectroscopy (fNIRS) to further establish the functional relationship between regions in PPC underlying spatial and numerical cognition. During a numerical magnitude comparison task, they found increased hemodynamic response related to the SNARC effect in bilateral IPS that was modulated by numerical distance, in addition to left angular gyrus activation. This interaction between the SNARC and numerical distance is somewhat surprising given that other behavioral studies have suggested these effects are independent (e.g. Gibson and Maurer, 2016; Herrera et al., 2008; Toomarian and Hubbard, 2017). However, as other studies have found these effects to be correlated (e.g. Viarouge et al., 2014), more research is clearly necessary to further characterize the interplay between spatial associations of number and numerical distance. Furthermore, it is possible that fNIRS might not 
be a sensitive enough tool to disentangle these two responses. This debate notwithstanding, these findings do implicate both the IPS and angular gyrus as components of the frontal-parietal network underlying spatial-numerical associations.

A recent study using fMRI sought to explicitly disentangle functional regions of the IPS based on numerical magnitude or spatial position (Kanayet et al., 2017). By employing a number line estimation task with distinct windows for encoding (mentally representing the presented number) and marking (making their selection for where the number would go on the line), Kanayet and colleagues were able to distinguish between the cognitive and motor processes involved in the task. During the encoding phase, they found a functional dissociation between anterior and posterior IPS, with the former associated with numerical magnitude and the latter with spatial positioning. This finding may help account for the implication of IPS/PPC in studies of both numerical and spatial processing.

However, the role of PPC in underlying the SNARC effect has recently been challenged by Di Rosa and colleagues (2017). They found that application of transcranial direct current stimulation (tDCS) to PPC during a parity judgement task did not modulate the SNARC effect, regardless of whether the stimulation was excitatory or inhibitory. An earlier neuromodulation study (Rusconi et al., 2007) found that rTMS applied to posterior IPS reduced the SNARC effect, but did not eliminate it. This suggests that the posterior PPC is at least partially responsible for SNARC, but that other regions likely also play a supporting role. Taken together, these results suggest some dissociation between PPC and the SNARC effect and provide support for a more distributed network of neural regions supporting spatial-numerical associations.

In line with this conceptualization of a widespread network supporting SNAs are the findings of Koten et al. (2011), who used a unique numerical landmark task and both univariate 
and multivariate analytical techniques to investigate the interaction of spatial and numerical representations in the brain. In the multivariate analysis, they found evidence that the IPS, frontal eye fields and supplementary motor areas work together to integrate numerical and spatial information. Interestingly, when spatially-congruent trials were compared against incongruent trials in a classic generalized linear model (GLM) analysis, no regions showed significant activation to this contrast. This is consistent with Goffaux et al. (2012), who found bilateral parietal activation based on digit magnitude (large/small) but no evidence of SNARC in IPS/IPL during a color-discrimination cuing task with irrelevant number stimuli. Taken together, these studies underscore that there is mixed evidence for PPC as the central locus of SNAs.

\subsection{Role of Frontal Regions}

Beyond the IPS and angular gyrus, more anterior cortical regions also play a role in spatial-numerical associations. In an ERP study, Ranzini et al. (2009) discovered involvement of frontal components in response to endogenous shifts of attention induced by numerical stimuli, in addition to a more posterior, parietal component. Other more anterior regions of the brain, specifically right inferior frontal gyrus (rIFG) and right frontal eye fields (rFEF), have also been implicated in spatial orienting of the mental number line (Rusconi et al., 2013, 2011). These anterior attention areas may be involved in orienting attention during spatial search, particularly during tasks with magnitude-relevant components. Indeed, when rTMS was applied to these two areas to disrupt functioning, the SNARC effect during magnitude comparison disappeared, whereas it was unaffected during a parity task (Rusconi et al., 2011). Notably, overall task performance was also unaffected. These results suggest that frontal areas may also play a role in conceptual space of the MNL. 
Taken together, the neural evidence reviewed in this section implicates a distributed frontoparietal network that underlies spatial-numerical associations. However, the precise nature of these networks, including how they develop, is yet unknown. Additional research that specifically and directly investigates the nature of neural representations of SNAs is still sorely needed.

\section{Theories of Spatial and Numerical Cognition}

In this section, we discuss the cognitive developmental theories that contextualize the previously discussed empirical findings. While several of these theoretical frameworks include the dimensions of space, time and number, we will limit discussion of the temporal component for the sake of brevity (for a review of time-space interactions, see Bonato et al., 2012). Instead, we will focus on how each of these theories applies specifically to spatial-numerical associations and support weak intrinsic biases that arise early in development.

\subsection{A Theory of Magnitude}

One of the first general conceptual frameworks that accounted for commonalities between human processing of time, space and quantity is Walsh's influential "A Theory of Magnitude” (ATOM; 2003). Inspired by Critchley’s (1953) classic neuropsychological investigations of the functions of the parietal lobe, Walsh integrates more recent behavioral and neuroscientific evidence to posit that magnitude is the shared property and underlying basis for the associations between space, time and number. For example, in the domain of space and quantity, numerical magnitude is the determinant of distance and SNARC effects, and space, time and quantity are associated with overlapping brain regions in parietal cortex (Dehaene and Brannon, 2011; Hubbard et al., 2005). 
Bueti \& Walsh (2009) subsequently followed up on some of the original ATOM predictions, and delved further into the phylogenetic influences of the proposed parietal magnitude system. They posit that the parietal cortex is a logical location for the evolutionarilyadvanced/late ability to count discrete objects (the first step in higher-order mathematical thinking), because the system would already be equipped to handle similar "issues" related to spatial and temporal magnitude (e.g. "nearer-farther", "faster-slower", "more than-less than"). In particular, they cite the evolutionary efficiency of a general magnitude representation in parietal cortex, an idea reminiscent of the more general neural theory of "neuronal recycling" (Dehaene, 2005; Dehaene and Cohen, 2007), which will be discussed further in 5.1. Such a theory is supported by evidence of topographic maps for magnitude-relevant properties in parietal cortex (Harvey et al., 2013).

Furthermore, as initially predicted by ATOM, the SNARC does indeed appear to be a specific instantiation of a much broader tendency to map quantities to space. Thus, the SNARC might be considered part of a broader "Spatial-Quantity Association of Response Codes" (SQUARC) effect (Bueti and Walsh, 2009; Kirjakovski and Utsuki, 2012; Walsh, 2003). This sensitivity to non-symbolic quantity may also be understood as a sensitivity to magnitude more broadly (Leibovich et al., 2016). Bueti \& Walsh used the visual system as a model for understanding magnitude processing: initially, areas coding for color, motion and form in visual cortex were thought to be discrete, but we now know that neurons simultaneously code for several properties, such as color and orientation, within the visual system (e.g. Rentzeperis et al., 2014). Similarly, the research on numerical cognition currently seeks to identify individual neurons tuned to specific numerosities, when in reality these neural populations may serve several functions related to magnitude. One finding that is consistent with this "multiplexing" 
model comes from Tudusciuc and Nieder (2007). They found that cells in primate PPC responded not only to a preferred numerosity, but also that the same cells responded preferentially to specific line-lengths (see also Tudusciuc and Nieder, 2009). Interestingly, some cells in primate PPC that are tuned to number are also tuned to visual motion direction (Nieder et al., 2006). More sophisticated neuroimaging techniques, such as multivariate pattern analysis, may help to elucidate the subtle nature of these possible differentiations in parietal cortex.

Several accounts have posited that the parietal cortex processes magnitude representations independent of dimension (Bueti and Walsh, 2009; Holloway and Ansari, 2010; Piazza et al., 2007), including numerical and spatial magnitudes (Cohen Kadosh et al., 2005; Pinel et al., 2004) and possibly temporal magnitudes as well (Gijssels et al., 2013). Such accounts provide support for the central principles of ATOM. For instance, the right IPS is thought to play a particularly important role in format-independent numerical magnitude representations, with increasing specialization occurring with increasing age (Holloway and Ansari, 2010). Additionally, the IPS appears to respond to ordinality as well as cardinal numerical magnitude (Franklin and Jonides, 2009; but see Van Opstal et al., 2009). Although the same neural regions are activated for ordinal and cardinal number processing, machine-learning techniques can distinguish between cardinal and ordinal number processing within IPS (Zorzi et al., 2011). Notably, a recent study demonstrated a dissociation between the neural correlates for time-space and number-space associations in the parietal lobe. Riemer et al. (2016) used transcranial magnetic stimulation (TMS) to inhibit the IPS immediately prior to several tests of response code association. They found that this impairment modulated tasks of time-space association but not number-space associations (measured by the SNARC). Further studies are needed to more fully explain and replicate these results, as they are the first to demonstrate such 
a strong dissociation between the MNL and the mental time line and thus challenge a central prediction made by ATOM.

\subsection{Generalized Magnitude System}

While ATOM describes magnitude processing in adults from a neural and psychological perspective, it does not offer a framework for how this magnitude system develops. To what extent do magnitude representations overlap, and what is their developmental trajectory? Do infants have an initially undifferentiated sensitivity to magnitudes, which then distinguishes among dimensions through experience in the world, or does experience with these dimensions lead to an extraction of magnitude as the underlying link? The answers to these questions have great potential to influence our understanding of SNAs, but studies with adults are insufficient for understanding whether the relationship between magnitude and dimensions such as quantity, time, size, space, etc. occurs in a top-down or bottom-up fashion. Rather, data from developmental samples afford the necessary perspective for such broad questions.

The two possible developmental trajectories noted above lead to several hypotheses that have been empirically tested. If humans are born with an initially undifferentiated "generalized magnitude system," (GMS) there should be evidence of transfer and interference effects across magnitude dimensions early in development (Newcombe et al., 2015). Early work by Piaget (1952) opened a window into the intertwined development of number and spatial extent, with his use of a number conservation task. Children were likely to say that an array of objects with more space between them had "more" than an equally numerous, less spaced-out array. This effect persisted until middle childhood, suggesting that these dimensions required time and experience to differentiate from their shared base of understanding. More recently, in a set of two experiments with 9-month old (preverbal) infants, Lourenco and Longo (2010) demonstrated 
associative transfer effects across the dimensions of size, numerosity, and duration. Preverbal infants expect that larger objects will be more numerous, last longer, and generalize across related dimensions of magnitude. Similar results have been described by de Hevia and colleagues, with evidence that both 8-month old infants (de Hevia and Spelke, 2010) and even hours-old neonates (de Hevia et al., 2014b) transfer their understanding of ordered (increasing or decreasing) numerosities to ordered line lengths, and vice versa. These results demonstrate an extremely early association between numerosity and spatial extent, leaving little room for any experiential or linguistic factors to contribute to these effects. Because these effects emerge prior to language development, a verbal-spatial account of the SNARC cannot be the primary source of SNAs, though they may influence direction and strength of association later in the course of development.

While humans may initially be sensitive to both numerical and non-numerical magnitudes, these representations become more differentiated with development. For example, knowledge of both numerical and non-numerical magnitudes has been shown to predict math performance in 5-6-year olds (Lourenco and Bonny, 2016) and adults (Lourenco et al., 2012), yet each contributes unique variance to various measures of math knowledge. Additionally, Skagerlund and Träff (2016) found that space, time, and number all contribute to different components of math ability in 8 - to 10 -year old children, implying that magnitude processing underlies math achievement generally, and that these dimensions may already begin to differentiate by mid-childhood. These studies suggest that numerical and non-numerical magnitudes are only partially — rather than fully—integrated even in adulthood. In light of these and other findings, some have argued against the previously dominant view that humans have an innate "number sense," advocating instead that a developing, more general sensitivity to 
continuous magnitude may provide a more complete account (see Leibovich et al. (2016) and associated commentaries).

A key question arises as a result of these studies- do numbers and space have a privileged relationship early in development? de Hevia and Spelke (2010) argue that human infants are predisposed to link numbers and space specifically, while Lourenco and Longo (2010) assert that the associations are a result of an undifferentiated system tuned to magnitudes broadly. In our view, the presence of transfer effects for infants across dimensions of number, size, and duration certainly points toward an early, broad understanding of both numerical and non-numerical magnitude. Starr and Brannon (2015) also take this more middle-of-the-road stance, suggesting some magnitude dimensions are in place early in development (privileged), while others emerge later, after additional experiential input. In a test between number-pitch and number-space judgments, Marghetis et al. (2011) found that participants were faster to associate high pitches with larger numbers. Since they found a relationship between pitch and number that is similar to that observed for numbers and space, Marghetis et al. argue that the link between space and number cannot be privileged in the way that others suggest. Note, however, that their finding of a positive relationship between pitch and number is not inconsistent with the broad stance of a generalized magnitude system. Indeed, the authors acknowledge that their results could be explained by a sensitivity to magnitudes generally, or an even broader capacity for conceptual mapping. Since both numbers and pitches are mapped to space (e.g. Bruzzi et al., 2017; Rusconi et al., 2006), pitch may be another non-numerical magnitude that is part of the GMS. Ultimately, the degree of overlap between these magnitude mappings is still unclear, as the current findings do not allow for an interpretation that moves beyond "privileged/not privileged." Further 
research is needed to clearly understand any possible hierarchy among these dimensions of magnitude, or whether cultural convention establishes such a hierarchy.

Studies of atypical numerical development can further aid in understanding the role of magnitude in spatial-numerical development. Skagerlund and Träff (2014) demonstrated that children with developmental dyscalculia (DD) not only had difficulty with non-symbolic numerical approximation (reduced approximate numerical acuity), but also showed deficits in tasks related to time and space, supporting the existence of a shared mechanism for magnitude processing. Neuroimaging studies have provided some support for this hypothesis, with adjacent and overlapping magnitude representations for number, spatial extent, and duration in frontalparietal circuits (e.g. Cohen Kadosh et al., 2008; Piazza et al., 2007). Dumontheil and Klingberg (2012) showed that extent of IPS activation during a visuospatial WM task predicted later math difficulties better than behavioral measures alone, providing support for the link between numerical and visuospatial abilities (but see Crollen and Noël, 2015). A recent study of adults with DD only partially corroborated the findings of Skagerland and Träff (2014), demonstrating impairment in numerosity and duration processing, but no impairment in length judgements (De Visscher et al., 2017). Additional studies with participants with math difficulties would help establish a higher level of clarity concerning intertwined processing of space, time and number, including whether any these dimensions have "privileged" status.

\subsection{Integrated Theory of Numerical Development}

Another useful theoretical framework for understanding the development of numerical magnitude knowledge, and particularly relevant to the development of spatial-numerical associations, is the integrated theory of numerical development (Siegler et al., 2011). In this view, numerical development is described as a broadening understanding of magnitudes, 
beginning with representations of non-symbolic magnitudes, linking magnitudes to symbols, and extending to understanding of all rational magnitudes (Siegler, 2016; Siegler et al., 2011). The key unifying theme throughout numerical development is a broadening understanding of numerical magnitude (Siegler, 2016), which is generally consistent with the generalized magnitude system described above. Indeed, in the updated theory, Siegler suggests that this unifying framework for numbers can and should be adapted to apply to other magnitude-relevant domains.

A key component of the integrated theory is the understanding that all numerical magnitudes can be represented on physical number lines, and thus should be mentally represented on a number line as well. In this construction and usage of a spatial, mental number line, the roles of associative learning and conceptual metaphor are critical (Nunez and Lakoff, 2005; Winter et al., 2015a). Students must understand that the spatial representation of magnitude that they hold in their mind can be mapped onto magnitudes they experience out in the world. This concept is related to the notion of a "central numerical structure" (Case et al., 1996), which also emphasizes spatial organization of a MNL, but incorporates aspects of verbalspatial learning and cognitive flexibility as numerical understanding broadens.

This theoretical framework for numerical development has been bolstered by studies that demonstrate a predictive link between knowledge of numerical magnitude and measures of math achievement (Booth and Siegler, 2008; Fazio et al., 2014; Sasanguie et al., 2013). For example, Booth and Siegler (2008) found that first graders' numerical magnitude representation (on a physical number line) was predictive of their arithmetic performance. Furthermore, students who looked at and/or produced visual images of numerical magnitudes on a number line before doing arithmetic problems subsequently learned those problems better. Such results reinforce the causal 
role of magnitude representations in simple mathematical problem solving, and dovetail with the central tenet of the generalized magnitude system. Importantly, the integrated theory does not, in either the original or expanded form, offer a prediction about whether magnitude is an innate human sensitivity or if it arises from experience with the world. Rather, it serves as "a useful unifying theme for understanding numerical development from infancy through adulthood" (Siegler, 2016, p. 353).

Taken together, ATOM, GMS, and the integrated theory of numerical development all propose that magnitude processing is a key concept that likely undergirds the association between space and number in the brain. Additionally, while these theories make similar predications regarding magnitude processing, they stem from very different academic traditions. For instance, ATOM derives from neuropsychological and neuroimaging data in adults, while GMS comes from a developmental psychology perspective. Thus, bringing together these theoretical frameworks is an important step towards a more unified understanding of magnitude development. Additionally, while a wide range of empirical studies appear to converge to support magnitude as the common construct underlying SNA, the privileged status of SNAs remains an open question. To date, these theories of numerical development have not been explicitly integrated with neural theories supporting spatial-numerical associations. In the following section, we will review relevant theories of neural development to provide this explicit integration between neural and developmental theories of SNAs.

\section{Neural Theories of Development}

A discussion of the relevant cognitive neuroscience theories of development may help to resolve the apparent debate between innately prespecified and culturally acquired views of SNAs. Indeed, a deeper understanding of the phylogenetic development of SNAs grounds 
several of the previously discussed theories of ontogenetic development. In this section, we primarily discuss two relevant and complementary accounts of the development of the cortical regions and functional pathways that underlie the ability to link spatial and numerical cognition. Both theories move beyond the obsolete nature vs. nurture dichotomy by allowing for both neural biasing and cultural modification. We also discuss how this development may lead to deep connections between space and number in mathematical thinking.

\subsection{Neuronal Recycling}

The ability to assign numerical magnitude to arbitrary symbols is uniquely human and is the basis for our ability to construct and comprehend complex mathematics. However, this ability is fairly recent when placed in perspective of the evolutionary timeline of the human brain. The neuronal recycling hypothesis aims to provide an account for this and other relatively recent, culturally-transmitted abilities such as reading (Dehaene, 2005; Dehaene and Cohen, 2007). In this view, these newer abilities co-opt evolutionarily older neural circuitry for more recent functionality, and thus are constrained by the existing structure of the brain. The designated circuits must have sufficiently close functionality to be able to support the new usage, and while the original circuits will adjust to accommodate the new skill or purpose, they will exact constraints that ultimately influence functionality (Dehaene and Cohen, 2007).

With regard to the origins of these cortical maps, neuronal recycling allows for a nuanced view of how they come into place. There is an undeniable continuity and consistency in human cortical mapping, with large-scale functional specificity preserved across cultures, such as vision primarily in occipital lobes. However, epigenetic changes based on postnatal sensory inputs refine these large-scale maps, allowing for subtle individual variation in functional specification of these regions. This theory helps to make sense of the wide array of functions that are 
subserved by parietal cortex, including manual grasping, shifts of attention, exact calculation, saccades, etc. For example, a cortical region in PPC devoted to shifts of spatial attention, which is a broad and important general ability, may be co-opted to shift attention along a spatial mental number line (Hubbard et al., 2009). In this way, cortical regions and even entire circuits may be repurposed to suit evolutionarily new and culturally specified cognitive demands. Eventually, differential experience with language, finger counting, and other cultural activities likely shape the unique neural and behavioral profile of individuals.

\subsection{Interactive specialization}

Interactive specialization (IS) is a domain-general framework for the ontogenetic development of human brain functions. The IS framework accounts for shortcomings in other, more extreme theories of functional brain development by taking a more nuanced approach (Johnson, 2011). Specifically, this view supposes a bi-directional relationship between structure and function; activity-dependent interactions between cortical regions result in refined functional specificity and response properties. Furthermore, this refined theory clarifies that changes in response patterns in one region are determined by patterns of connectivity with other regions, resulting in network-wide changes in functionality, not simply one region (Johnson, 2011). This aspect of IS further exemplifies its fit as an account of SNAs, as they are the product of a frontalparietal network that develops with age and experience. Additionally, it enhances the view that spatial cognition and numerical cognition can develop simultaneously and harmoniously, as part

of a generalized magnitude system, and thereby give rise to SNAs, which occur as a result of interactive specialization.

An important consideration in the application of these theories to the development of SNAs is the role of plasticity and cognitive flexibility. Behavioral evidence has shown that SNAs 
not only change over an individual's course of development, but they are also flexible and easily influenced by task demands and task instructions (Georges et al., 2014; Li et al., 2016; Pfister et al., 2013). Such evidence suggests at least some functional flexibility of SNAs, consistent with the view that there is not a single, static MNL. Instead, we argue that SNAs arise from a multitude of cognitive processes and may be reflected in multiple representations (see also Basso Moro et al., 2017). We know that there is the ability to influence the SNARC effect in groups and individuals, but we do not know what the accompanying neural signature of this change would look like. Is there a sensitive period for developing SNAs? For instance, if a group without any trace of a classic SNARC effect (e.g. monolingual Hebrew-speakers) underwent training to encourage number-space mappings, would the functional specificity of frontalparietal regions change accordingly? Would this intervention have to happen in childhood? The IS view would predict that functional specificity of these cortical regions would be less likely to change in adulthood. Carefully designed empirical studies are needed to test these hypotheses.

\section{Co-Construction of the Mental Number Line}

\subsection{Integrating Developmental Cognitive Neuroscience Accounts}

Both neuronal recycling and interactive specialization provide a useful structure onto which we can frame our understanding of SNAs. We posit that the evolutionarily ancient parietal structure provides an appropriate niche for high level, symbolic numerical processing, with nonsymbolic/magnitude processing as its basis. This is the basis for spatial-numerical associations broadly. Then, as informed by the IS account, over the course of an individual's development, their sensory experiences with magnitudes as well as through cultural experiences with activities such as language and gesture, influence the intra-regional functional specificity in posterior parietal regions. This sequence of events during development thus influences the unique profile 
of one's SNA, and accounts for individual differences. This is how we can explain the data indicating cultural differences in the form and direction of SNAs, as well as evidence of SNAs in newborn chicks and preverbal infants. There is some intrinsic bias toward associated numbers and space, and then experience with the world and with others determines the extent and profile of the association. Indeed, Winter et al. (2015b) have proposed a framework complementary to our bottom-up approach. They suggest that mental spatial mappings arise through a process of “converging cultural support," including constraints from physical embodiment and brain organization.

Additional empirical studies using developmental cognitive neuroscience methods are necessary to confirm this holistic account of the formation of SNAs. Ideally, the same human infants who participate in studies early in development, such as those by de Hevia and colleagues, would be tracked over the course of their childhood. Then, researchers could take an individual differences approach and study the factors known to contribute to variability in SNAs (e.g. exposure to other languages and cultures, early numeracy abilities, etc.). Regular functional and structural imaging of regions of interest (i.e. frontal-parietal networks) could supplement these behavioral measures, to provide a nuanced and complete account of development of SNAs. Ultimately, a better understanding of this process has the potential to be useful for informing instructional techniques and approaches to spatial and numerical activities.

\subsection{An Integrated Vision of SNAs}

One recurring theme throughout the investigation of the origins and developmental influences of SNAs has been whether they emerge as the result of predetermined, intrinsic factors or through interaction with extrinsic, sensorimotor experience in the world. This debate has been addressed in the context of neural functional and structural development. However, the 
framing of these two views as mutually exclusive or as universally true is outdated and inaccurate. The admission of an interaction between dynamic factors does not invalidate research that supports one view or the other; rather, it integrates and grounds the disparate research findings into a unified and comprehensive understanding of how space and number become intertwined in the mind.

The empirical research and theoretical approaches discussed throughout this review point to an evolutionarily ancient frontal-parietal circuit that is broadly tuned to process multiple dimensions of magnitude. These sensitivities are modeled well by theories of a generalized magnitude system as well as the integrated theory of numerical development. Neuronal recycling of frontoparietal regions provides the phylogenetic substrate for SNAs, and interactive specialization helps account for ontogenetic development. Enculturation and sensorimotor experience shape the specific profile of these SNAs, leading to the ample evidence of crosscultural differences and cognitive flexibility of the MNL. Although the tension between biological pre-specification and experience dependency still persists, there is ultimately more room to effect change in applied domains such as pedagogy when one takes an interactive specialization approach. If spatial and numerical skills are indeed intertwined and influenced over the course of development, there is the opportunity to leverage this process for the purposes of intervention.

\section{Implications for Learning}

The developing association between numbers and space is one possible avenue through which cognitive psychology and neuroscience may be able to inform instruction. There are several reasons why this may be a worthwhile endeavor. First, while evidence of SNAs is apparent even in preverbal infants, more explicit markers such as the SNARC appear to emerge 
and consolidate during mid-childhood. Thus, instructional techniques employed in early to midchildhood may differentially affect the profile of individual students' SNAs. Second, several behavioral studies have demonstrated that early numerical magnitude understanding is indeed correlated with arithmetic knowledge and is predictive of learning unfamiliar problems, even when controlling for factors such as memory and prior arithmetic knowledge (Booth and Siegler, 2008; see also Sasanguie et al., 2012). Under the assumption that SNAs arise as the result of the underlying property of magnitude, these findings highlight the importance of strong spatial understanding of magnitudes on the MNL. It is worth noting, however, that studies attempting to link individual differences in the SNARC effect to outcomes such as arithmetic performance have yielded mixed results. Some studies have failed to find a relationship between strength of SNAs in childhood and math performance (Gibson and Maurer, 2016; Schneider et al., 2009), while others have found positive evidence for such a link (Georges et al., 2017; Hoffmann et al., 2013). As detailed in a recent review by Cipora et al. (2015), links between SNAs and math skills are generally inconsistent and the directionality of this relationship (i.e. whether SNAs impact arithmetic ability or vice versa) has yet to be established. However, space-number mappings and metaphors are still powerful educational tools. Indeed, as we will discuss in this section, a number of training and remediation paradigms have demonstrated that simple, spatially-rooted, game-based interventions may improve internal representations of magnitudes on a mental number line.

\subsection{The Relationship Between Spatial and Math Skills}

The development of spatial and numeracy skills are unique predictors of later mathematical success and other academic outcomes (for a review, see Mix and Cheng, 2012). For example, in a review of two long-term longitudinal studies spanning from the 1960 s to the 
present, spatial skills in high school students were predictive of whether they would go on to pursue a career in STEM fields 11 years later (Wai et al., 2009). In light of this predictive quality, the authors propose that spatial skills, in addition to numeracy skills, may be a useful metric for the placement of students in advanced academic programs (see Shea et al., 2001; Webb et al., 2007). Given that spatial skills and numerical abilities are predictive of later life success and also appear to be related to each other early on (Mix et al., 2016), we conjecture that their intertwined development should be uniquely predictive of mathematical proficiency. The ability to mentally represent numbers spatially, and to use those representations flexibly, should have a super-additive effect on cognitive outcomes, above and beyond just spatial or numerical abilities. Large scale, longitudinal studies investigating the development of SNAs are necessary to evaluate this hypothesis.

Training studies are necessary to establish causal links between spatial cognition and math ability. Despite the evidence that has linked spatial ability to broad STEM outcomes (Wai et al., 2009), there have been mixed results in studies employing explicit training studies. A meta-analysis of spatial training studies suggests that training does enhance spatial thinking, which improves STEM achievement, but does not provide strong evidence for a causal link (Uttal et al., 2013). A recent study by Cornu et al. (2017) also showed evidence of such domainspecificity. Children who were trained for ten weeks on a tablet-based visuospatial intervention showed improvement only in visuospatial skills but not math abilities. However, there has been some success in improving math ability with spatial training. A ten-week, classroom-based spatial reasoning program designed in conjunction with schoolteachers resulted in improved performance on both spatial and mathematical outcome measures (Lowrie et al., 2017). Furthermore, Cheng \& Mix (2014) showed that 6-to 8-year olds who trained on a mental rotation 
task for 40 minutes had improved calculation abilities as measured by a post-test, while a crossword puzzle control group did not. While these results are intriguing, there was no evidence that these effects endured, and no indication as to whether they might extend to other forms of spatial training. In another study with similar methods and an extended training period, there was no evidence of improved calculation ability following mental rotation training (Hawes et al., 2015). Notably, they employed a delayed post-test 3-6 days following the six week training, suggesting that calculation abilities may indeed improve immediately following mental rotation training, but these effects may not last. Taken together, these conflicting findings demonstrate the critical need for researchers to identify which mediating factors might explain the complex relationship between spatial training and mathematical outcomes.

Beyond spatial training studies, spatial-numerical associations may bolster the case for an individual differences approach to teaching and learning. For example, the absolute strength of preschoolers' individual SNAs led to stronger and more linear numerical representations, regardless of the direction of the SNA (Rinaldi et al., 2016). In another study with an individual approach, participants remembered a set of ordered stimuli better when they were presented in the direction congruent with the dominant directionality of their culture (McCrink and Shaki, 2016). However, the direction, strength, and reliance on SNAs may vary widely across a group, even within the same culture. Additionally, the relationship between individual SNAs and outcome measures of interest, such as arithmetic learning, is likely mediated by other factors (Cipora et al., 2015), such as performance on number line estimation task (Simms et al., 2016). Perhaps assessing an individual "baseline SNA" would be the optimal approach for structuring mathematics learning, or limiting interference effects from incongruent manipulatives or educational experiences. 


\subsection{Number Line Training}

Both numerical magnitude understanding and spatial thinking are predictive of later STEM success, and training studies have shown promise for encouraging this trend. However, despite these promising attempts to train both spatial ability and underlying numerical representations, considerably fewer studies have considered the added benefit of training these skills concurrently. Several studies have investigated whether explicitly training people to link spatial and numerical constructs (e.g. number line estimation) yields improvement in either a domain-specific or domain-general fashion. These studies have almost exclusively focused on two training paradigms: number line estimation tasks and numerical board games.

Drawing from the integrated theory of numerical development, knowing that all real numbers have magnitudes that can be spatially oriented and placed on a number line is crucial for mathematical development (Siegler et al., 2011). Number line estimation tasks aim to strengthen this link between physical number line and a mental representation of numerical magnitudes. Many studies have demonstrated a link between number line estimation abilities and various mathematical competence measures (Booth and Siegler, 2006; Friso-van den Bos et al., 2015; Muldoon et al., 2013; Siegler and Opfer, 2003; Simms et al., 2016), a pattern that was recently validated by a meta-analysis of such studies in childhood (Schneider et al., in press). Additionally, number line training has proven successful for both children with developmental dyscalculia and typical controls in improving spatial representation of numerical magnitudes and improving algebra (Kucian et al., 2011). The mechanism underlying these improvements (i.e. whether they truly strengthen underlying SNAs or are indicative of skills such as proportional reasoning) is still under debate (e.g. Link et al., 2014). 
Similar to number line estimation, board games that rely heavily on gameplay components reminiscent of number lines, such as Chutes and Ladders, have proven successful in improving a wide range of mathematically-relevant outcomes. Playing linear board games, but not circular ones, for as little as one hour has been shown to improve low-income preschoolers' ability to compare numerical magnitudes, place numbers on a number line, and answer arithmetic problems (Ramani and Siegler, 2008; Siegler and Ramani, 2009; see also Whyte and Bull, 2008). Furthermore, kindergarteners who trained for six weeks on a linear board game improved their performance on a number line estimation task relative to the circular game, counting game, and no-game/control groups, and also improved on a calculation task (Elofsson et al., 2016). These board games that utilize a linear spatial mapping for number may be successful for several reasons. One reason is the "representational mapping hypothesis," which posits that a transparent connection between game play and internal representation of number is key for developing a strong linear MNL representation (Siegler and Ramani, 2009). Another consideration is that these links between numbers and linear space in gameplay have a long history, surviving transmission through generations and across cultures. Similar to other cultural practices that promote positive cognitive outcomes, such as nursery rhymes and folk tales, their enduring appeal may be due not only to their entertainment value but also to their inherent cognitive effects. This idea of the "wisdom of culture" (Siegler and Ramani, 2009, pg. 556) as a process that preserves and transmits cultural inventions that are well adapted to our cognitive and neural architectures may help to account for the widespread nature and usage of SNAs, and provide motivation for further studying their educational implications. Indeed, this idea is complementary to Dehaene's notion of cultural co-evolution in his neuronal recycling theory, which posits that those representations best adapted to the evolutionary constraints of our neural 
systems are those that are most likely to be acquired, and in turn passed along. To this end, future studies should explicitly test the extent to which effects as a result of number line training endure, and if not, what changes might be necessary to ensure that they do.

On the basis of these collective findings, some researchers have suggested that more sophisticated technology—beyond single-player, computerized number line paradigms — might be a particularly promising avenue for training the mental number line (for a review, see Moeller et al., 2015). For instance, researchers might consider using paradigms with multi-player functionality (Moeller et al., 2015) and/or adaptive trainings that calibrate based on individual performance (e.g. Käser et al., 2013). Motion-sensitive devices that monitor participant body movements and gestures, in addition to others grounded in the embodied cognition view of SNA development (e.g. Fischer et al., 2016), may also prove beneficial for MNL training. A full-body approach to number line training has already proven effective at improving number line estimation and standardized math scores (Fischer et al., 2011).

\section{Conclusion}

The predictive relationship between spatial-numerical cognition and later STEM proficiency highlights the role of SNA development as a relevant issue for learning. This review incorporates research from across several fields and many methodologies to provide a broad picture of spatialnumerical associations. From theories regarding their origins and influences, to understanding how SNAs shape learning outcomes, there is a great deal of room for debate and exploration of this topic. We propose that space and number are deeply intertwined in the mind as a result of both neural biasing and cultural influence, and that all characterizations of SNAs should take into account the interplay of many factors. Future studies should endeavor to further disambiguate the 
relationship between these two dimensions of magnitude and investigate how their associations contribute to individual differences in mathematical thinking. 
Acknowledgements

This research was supported by the National Science Foundation (DGE-1256259) and the National Institutes of Health (NICHD 1R01HD088585). The opinions expressed are those of the authors and do not represent the views of the National Science Foundation or National Institutes of Health. We would like to thank Percival Matthews, Haley Vlach, John Binzak, Radhika Gosavi, Priya Kalra, Zachary Grulke and two anonymous reviewers for helpful comments on the manuscript. 


\section{References}

Abrahamse, E., Van Dijck, J.P., Fias, W., 2016. How does working memory enable numberinduced spatial biases? Front. Psychol. 7, 1-11. https://doi.org/10.3389/fpsyg.2016.00977

Adachi, I., 2014. Spontaneous spatial mapping of learned sequence in chimpanzees: Evidence for a SNARC-Like effect. PLoS One 9, 1-4. https://doi.org/10.1371/journal.pone.0090373

Aiello, M., Jacquin-Courtois, S., Merola, S., Ottaviani, T., Tomaiuolo, F., Bueti, D., Rossetti, Y., Doricchi, F., 2012. No inherent left and right side in human "mental number line": Evidence from right brain damage. Brain 135, 2492-2505. https://doi.org/10.1093/brain/aws1 14

Aiello, M., Merola, S., Doricchi, F., 2013. Small numbers in the right brain: Evidence from patients without and with spatial neglect. Cortex 49, 348-351. https://doi.org/10.1016/j.cortex.2012.06.002

Awh, E., Jonides, J., 2001. Overlapping mechanisms of attention and spatial working memory. Trends Cogn. Sci. 5, 119-126. https://doi.org/10.1016/S1364-6613(00)01593-X

Bächtold, D., Baumüller, M., Brugger, P., 1998. Stimulus-response compatibility in representational space. Neuropsychologia 36, 731-735. https://doi.org/10.1016/S00283932(98)00002-5

Basso Moro, S., Dell'Acqua, R., Cutini, S., 2017. The SNARC effect is not a unitary phenomenon. Psychon. Bull. Rev. 1-8. https://doi.org/10.3758/s13423-017-1408-3

Benton, A.L., 1992. Gerstmann's syndrome. Arch. Neurol. 49, 445-7.

Berch, D.B., Foley, E.J., Hill, R.J., Ryan, P.M., 1999. Extracting parity and magnitude from Arabic numerals: developmental changes in number processing and mental representation. J. Exp. Child Psychol. 74, 286-308. https://doi.org/10.1006/jecp.1999.2518

Bonato, M., Zorzi, M., Umilta, C., 2012. When time is space: Evidence for a mental time line. Neurosci. Biobehav. Rev. 36, 2257-2273. https://doi.org/10.1016/j.neubiorev.2012.08.007

Booth, J.L., Siegler, R.S., 2008. Numerical Magnitude Representations Influence Arithmetic Learning. Child Dev. 79, 1016-1031.

Booth, J.L., Siegler, R.S., 2006. Developmental and individual differences in pure numerical estimation. Dev. Psychol. 42, 189-201. https://doi.org/10.1037/0012-1649.41.6.189

Brozzoli, C., Ishihara, M., Göbel, S.M., Salemme, R., Rossetti, Y., Farnè, A., 2008. Touch perception reveals the dominance of spatial over digital representation of numbers. Proc. Natl. Acad. Sci. U. S. A. 105, 5644-8. https://doi.org/10.1073/pnas.0708414105

Bruzzi, E., Talamini, F., Priftis, K., Grassi, M., 2017. A SMARC Effect for Loudness. https://doi.org/10.1177/2041669517742175

Bueti, D., Walsh, V., 2009. The parietal cortex and the representation of time, space, number and other magnitudes. Philos. Trans. R. Soc. Lond. B. Biol. Sci. 364, 1831-1840. https://doi.org/10.1098/rstb.2009.0028

Bulf, H., de Hevia, M.D., Macchi Cassia, V., 2016. Small on the left, large on the right: Numbers 
orient visual attention onto space in preverbal infants. Dev. Sci. 19, 394-401. https://doi.org/10.1111/desc. 12315

Calabria, M., Rossetti, Y., 2005. Interference between number processing and line bisection: A methodology. Neuropsychologia 43, 779-783. https://doi.org/10.1016/j.neuropsychologia.2004.06.027

Cantlon, J.F., Cordes, S., Libertus, M.E., Brannon, E.M., 2009. Comment on "Log or Linear? Scale in Western and Amazonian Indigene Cultures ." Science (80-. ). 323, 38.

Case, R., Okamoto, Y., Griffin, S., McKeough, A., 1996. JSTOR: Monographs of the Society for Research in Child Development, Vol. 61, No. 1/2 (1996), pp. i+iii-vi+1-295. Monogr. ....

Chan, W.W.L., Wong, T.T.Y., 2016. The underlying number-space mapping among kindergarteners and its relation with early numerical abilities. J. Exp. Child Psychol. 148, 35-50. https://doi.org/10.1016/j.jecp.2016.03.010

Cheng, Y.L., Mix, K.S., 2014. Spatial Training Improves Children's Mathematics Ability. J. Cogn. Dev. 15, 2-11. https://doi.org/10.1080/15248372.2012.725186

Cipora, K., Patro, K., Nuerk, H.C., 2015. Are Spatial-Numerical Associations a Cornerstone for Arithmetic Learning? The Lack of Genuine Correlations Suggests No. Mind, Brain, Educ. 9, 190-206. https://doi.org/10.1111/mbe.12093

Claeys, K.G., Dupont, P., Cornette, L., Sunaert, S., Van Hecke, P., De Schutter, E., Orban, G.A., 2004. Color discrimination involves ventral and dorsal stream visual areas. Cereb. Cortex 14, 803-822. https://doi.org/10.1093/cercor/bhh040

Cohen Kadosh, R., Henik, A., Rubinsten, O., Mohr, H., Dori, H., Van De Ven, V., Zorzi, M., Hendler, T., Goebel, R., Linden, D.E.J., 2005. Are numbers special? The comparison systems of the human brain investigated by fMRI. Neuropsychologia 43, 1238-1248. https://doi.org/10.1016/j.neuropsychologia.2004.12.017

Cohen Kadosh, R., Lammertyn, J., Izard, V., 2008. Are numbers special? An overview of chronometric, neuroimaging, developmental and comparative studies of magnitude representation. Prog. Neurobiol. 84, 132-147. https://doi.org/10.1016/j.pneurobio.2007.11.001

Colling, L.J., Holcombe, A.O., 2017. Registered Replication Report: Fischer, Castel, Dodd, \& Pratt (2003) [WWW Document]. Retrieved from osf.io/he5za.

Cooperrider, K., Marghetis, T., Núñez, R., 2017. Where Does the Ordered Line Come From? Evidence From a Culture of Papua New Guinea. Psychol. Sci. 28, 599-608. https://doi.org/10.1177/0956797617691548

Cornu, V., Schiltz, C., Pazouki, T., Martin, R., 2017. Training early visuo-spatial abilities: A controlled classroom-based intervention study. Appl. Dev. Sci. 1-21. https://doi.org/10.1080/10888691.2016.1276835

Coslett, H.B., 1997. Neglect in vision and visual imagery: a double dissociation. Brain 120, $1163-1171$. 
Critchley, M., 1953. The parietal lobes. Hafner Press.

Crollen, V., Dormal, G., Seron, X., Lepore, F., Collignon, O., 2013. Embodied numbers: The role of vision in the development of number-space interactions. Cortex 49, 276-283. https://doi.org/10.1016/j.cortex.2011.11.006

Crollen, V., Noël, M.P., 2015. Spatial and numerical processing in children with high and low visuospatial abilities. J. Exp. Child Psychol. 132, 84-98. https://doi.org/10.1016/j.jecp.2014.12.006

Cutini, S., Scarpa, F., Scatturin, P., Dell'Acqua, R., Zorzi, M., 2014. Number-space interactions in the human parietal cortex: Enlightening the snarc effect with functional near-infrared spectroscopy. Cereb. Cortex 24, 444-451. https://doi.org/10.1093/cercor/bhs321

de Hevia, M.D., Girelli, L., Addabbo, M., Cassia, V.M., 2014a. Human infants' preference for left-to-right oriented increasing numerical sequences. PLoS One 9. https://doi.org/10.1371/journal.pone.0096412

de Hevia, M.D., Izard, V., Coubart, A., Spelke, E.S., Streri, A., 2014b. Representations of space, time, and number in neonates. Proc. Natl. Acad. Sci. U. S. A. 111, 4809-13. https://doi.org/10.1073/pnas.1323628111

de Hevia, M.D., Spelke, E.S., 2010. Number-Space Mapping in Human Infants. Psychol. Sci. 21, 653-660. https://doi.org/10.1177/0956797610366091.Number-Space

De Visscher, A., Noël, M.-P., Pesenti, M., Dormal, V., 2017. Developmental Dyscalculia in Adults: Beyond Numerical Magnitude Impairment. J. Learn. Disabil. 2221941773233. https://doi.org/10.1177/0022219417732338

Dehaene, S., 2005. From monkey brain to human brain : a Fyssen Foundation symposium, Fyssen Foundation symposium. https://doi.org/10.1002/ajhb.20556

Dehaene, S., 1997. The number sense: How the mind creates mathematics. Oxford University Press, New York.

Dehaene, S., 1996. The Organization of Brain Activations in Number Comparison: EventRelated Potentials and the Additive-Factors Method. J. Cogn. Neurosci. 8, 47-68. https://doi.org/10.1162/jocn.1996.8.1.47

Dehaene, S., Bossini, S., Giraux, P., 1993. The mental representation of parity and number magnitude. J. Exp. Psychol. Gen. https://doi.org/10.1037/0096-3445.122.3.371

Dehaene, S., Brannon, E., 2011. Space, time and number in the brain: searching for the foundations of mathematical thought, Attention and performance series. Elsevier Academic Press. https://doi.org/10.1016/B978-0-12-385948-8

Dehaene, S., Cohen, L., 2007. Cultural recycling of cortical maps. Neuron 56, 384-398. https://doi.org/10.1016/j.neuron.2007.10.004

Dehaene, S., Dupoux, E., Mehler, J., 1990. Is numerical comparison digital? Analogical and symbolic effects in two-digit number comparison. J. Exp. Psychol. Hum. Percept. Perform. 16, 626-641. https://doi.org/10.1037/0096-1523.16.3.626 
Dehaene, S., Izard, V., Spelke, E., Pica, P., 2008. Log or linear? Distinct intuitions of the number scale in western and Amazonian indigene cultures. Science (80-. ). 320, 1217-1220. https://doi.org/10.1126/science. 1156540

Dehaene, S., Piazza, M., Pinel, P., Cohen, L., 2003. THREE PARIETAL CIRCUITS FOR NUMBER PROCESSING. Cogntive Neuropsychol. 3294, 37-41. https://doi.org/10.1080/02643290244000239

Di Bono, M.G., Zorzi, M., 2013. The Spatial Representation of Numerical and Non-Numerical Ordered Sequences: Insights from a Random Generation Task. Q. J. Exp. Psychol. 66, 2348-2362. https://doi.org/10.1080/17470218.2013.779730

Di Rosa, E., Bardi, L., Umiltà, C., Masina, F., Forgione, M., Mapelli, D., 2017. Transcranial direct current stimulation (tDCS) reveals a dissociation between SNARC and MARC effects: Implication for the polarity correspondence account. Cortex 93, 68-78. https://doi.org/10.1016/j.cortex.2017.05.002

Dodd, M.D., Van der Stigchel, S., Adil Leghari, M., Fung, G., Kingstone, A., 2008. Attentional SNARC: There's something special about numbers (let us count the ways). Cognition 108, 810-818. https://doi.org/10.1016/j.cognition.2008.04.006

Dollman, J., Levine, W.H., 2016. Rapid communication: The mental number line dominates alternative, explicit coding of number magnitude. Q. J. Exp. Psychol. 69, 403-409. https://doi.org/10.1080/17470218.2015.1101146

Doricchi, F., Guariglia, P., Gasparini, M., Tomaiuolo, F., 2005. Dissociation between physical and mental number line bisection in right hemisphere brain damage. Nat. Neurosci. 8 , 1663-1665. https://doi.org/10.1038/nn1563

Drucker, C.B., Brannon, E.M., 2014. Rhesus monkeys (Macaca mulatta) map number onto space. Cognition 132, 57-67. https://doi.org/10.1016/j.cognition.2014.03.011

Dumontheil, I., Klingberg, T., 2012. Brain activity during a visuospatial working memory task predicts arithmetical performance 2 years later. Cereb. Cortex 22, 1078-1085. https://doi.org/10.1093/cercor/bhr175

Elofsson, J., Gustafson, S., Samuelsson, J., Träff, U., 2016. Playing number board games supports 5-year-old children's early mathematical development. J. Math. Behav. 43, 134147. https://doi.org/10.1016/j.jmathb.2016.07.003

Fabbri, M., Guarini, A., 2016. Finger counting habit and spatial-numerical association in children and adults. Conscious. Cogn. 40, 45-53. https://doi.org/10.1016/j.concog.2015.12.012

Fattorini, E., Pinto, M., Rotondaro, F., Doricchi, F., 2015. Perceiving numbers does not cause automatic shifts of spatial attention. Cortex 73, 298-316. https://doi.org/10.1016/j.cortex.2015.09.007

Fazio, L.K., Bailey, D.H., Thompson, C.A., Siegler, R.S., 2014. Relations of different types of numerical magnitude representations to each other and to mathematics achievement. J. Exp. Child Psychol. 123, 53-72. https://doi.org/10.1016/j.jecp.2014.01.013 
Fias, W., Brysbaert, M., Geypens, F., D’Ydewalle, G., 1996. The importance of magnitude information in numerical processing: Evidence from the SNARC effect. Math. Cogn. 2, 95110. https://doi.org/10.1080/135467996387552

Fias, W., Dijck, J. Van, 2016. The Temporary Nature of Number — Space Interactions 70, 3340. https://doi.org/10.1037/cep0000071

Fias, W., Lauwereyns, J., Lammertyn, J., 2001. Irrelevant digits affect feature-based attention depending on the overlap of neural circuits. Cogn. Brain Res. 12, 415-423. https://doi.org/10.1016/S0926-6410(01)00078-7

Fias, W., van Dijck, J.P., Gevers, W., 2011. How is Number Associated with Space? The Role of Working Memory, in: Space, Time and Number in the Brain. pp. 133-148. https://doi.org/10.1016/B978-0-12-385948-8.00010-4

Fischer, M.H., 2008. Finger counting habits modulate spatial-numerical associations. Cortex 44, 386-392. https://doi.org/10.1016/j.cortex.2007.08.004

Fischer, M.H., Brugger, P., 2011. When digits help digits: Spatial-numerical associations point to finger counting as prime example of embodied cognition. Front. Psychol. 2, 1-7. https://doi.org/10.3389/fpsyg.2011.00260

Fischer, M.H., Castel, A.D., Dodd, M.D., Pratt, J., 2003. Perceiving numbers causes spatial shifts of attention. Nat. Neurosci. 6, 555-556. https://doi.org/10.1038/nn1066

Fischer, M.H., Mills, R.A., Shaki, S., 2010. How to cook a SNARC: Number placement in text rapidly changes spatial-numerical associations. Brain Cogn. 72, 333-336. https://doi.org/10.1016/J.BANDC.2009.10.010

Fischer, U., Moeller, K., Bientzle, M., Cress, U., Nuerk, H.-C., 2011. Sensori-motor spatial training of number magnitude representation. Psychon. Bull. Rev. 18, 177-183. https://doi.org/10.3758/s13423-010-0031-3

Fischer, U., Moeller, K., Class, F., Huber, S., Cress, U., Nuerk, H.-C., 2016. Dancing with the SNARC: Measuring spatial-numerical associations on a digital dance mat. Can. J. Exp. Psychol. Can. Psychol. expérimentale 70, 306-315. https://doi.org/10.1037/cep0000084

Franklin, M.S., Jonides, J., 2009. Order and magnitude share a common representation in parietal cortex. J. Cogn. Neurosci. 21, 2114-2120. https://doi.org/10.1162/jocn.2008.21181

Friso-van den Bos, I., Kroesbergen, E.H., Van Luit, J.E.H., Xenidou-Dervou, I., Jonkman, L.M., Van der Schoot, M., Van Lieshout, E.C.D.M., 2015. Longitudinal development of number line estimation and mathematics performance in primary school children. J. Exp. Child Psychol. 134, 12-29. https://doi.org/10.1016/j.jecp.2015.02.002

Galfano, G., Rusconi, E., Umiltà, C., 2006. Number magnitude orients attention, but not against one's will. Psychon. Bull. Rev. 13, 869-74. https://doi.org/10.3758/BF03194011

Gazes, R.P., Diamond, R.F.L., Hope, J.M., Caillaud, D., Stoinski, T.S., Hampton, R.R., 2017. Spatial representation of magnitude in gorillas and orangutans. Cognition 168, 312-319. https://doi.org/10.1016/j.cognition.2017.07.010 
Georges, C., Hoffmann, D., Schiltz, C., 2017. Mathematical abilities in elementary school: Do they relate to number-space associations? J. Exp. Child Psychol. 161, 126-147. https://doi.org/10.1016/j.jecp.2017.04.011

Georges, C., Schiltz, C., Hoffmann, D., 2014. Task instructions determine the visuo-spatial and verbal-spatial nature of number-space associations. Q. J. Exp. Psychol. (Hove). 218, 1-37. https://doi.org/10.1080/17470218.2014.997764

Gerstmann, J., 1940. Syndrome of finger agnosia, disorientation for right and left, agraphia and acalculia: Local diagnostic value. Arch. Neurol. Psychiatry 44, 398-408. https://doi.org/10.1001/archneurpsyc.1940.02280080158009

Gevers, W., Reynvoet, B., Fias, W., 2004. The Mental Representation of Ordinal Sequences is Spatially Organised: Evidence from Days of the Week. Cortex 40, 171-172. https://doi.org/10.1016/S0010-9452(08)70938-9

Gevers, W., Reynvoet, B., Fias, W., 2003. The mental representation of ordinal sequences is spatially organized. Cognition 87, B87-B95. https://doi.org/10.1016/S0010-0277(02)002342

Gevers, W., Santens, S., Dhooge, E., Chen, Q., Van den Bossche, L., Fias, W., Verguts, T., 2010. Verbal-spatial and visuospatial coding of number-space interactions. J. Exp. Psychol. Gen. 139, 180-190. https://doi.org/10.1037/a0017688

Gibson, L.C., Maurer, D., 2016. Development of SNARC and distance effects and their relation to mathematical and visuospatial abilities. J. Exp. Child Psychol. 150, 301-313. https://doi.org/10.1016/j.jecp.2016.05.009

Gijssels, T., Bottini, R., Rueschemeyer, S.-A., Casasanto, D., 2013. Space and time in the parietal cortex: fMRI Evidence for a meural asymmetry, in: Proceedings of the 35 th Annual Conference of the Cognitive Science Society. Austin, TX, pp. 495-500.

Ginsburg, V., Gevers, W., 2015. Spatial coding of ordinal information in short- and long-term memory. Front. Hum. Neurosci. 9, 1-10. https://doi.org/10.3389/fnhum.2015.00008

Göbel, S.M., Calabria, M., Farnè, A., Rossetti, Y., 2006. Parietal rTMS distorts the mental number line: Simulating "spatial" neglect in healthy subjects. Neuropsychologia 44, 860868. https://doi.org/10.1016/j.neuropsychologia.2005.09.007

Göbel, S.M., Shaki, S., Fischer, M.H., 2011. The Cultural Number Line : A Review of Cultural and Linguistic Influences on the Development of Number Processing. J. Cross. Cult. Psychol. 42, 543-565. https://doi.org/10.1177/0022022111406251

Goffaux, V., Martin, R., Dormal, G., Goebel, R., Schiltz, C., 2012. Attentional shifts induced by uninformative number symbols modulate neural activity in human occipital cortex. Neuropsychologia 50, 3419-3428. https://doi.org/10.1016/j.neuropsychologia.2012.09.046

Guariglia, C., Palermo, L., Piccardi, L., Iaria, G., Incoccia, C., 2013. Neglecting the left side of a city square but not the left side of its clock: prevalence and characteristics of representational neglect. PLoS One 8, e67390. https://doi.org/10.1371/journal.pone.0067390 
Harvey, B.M., Klein, B.P., Petridou, N., Dumoulin, S.O., 2013. Topographic Representation of Numerosity in the Human Parietal Cortex. Science (80-. ). 341, 1123-1126.

Haun, D.B.M., Jordan, F.M., Vallortigara, G., Clayton, N.S., 2011. Origins of Spatial, Temporal, and Numerical Cognition: Insights from Comparative Psychology, in: Space, Time and Number in the Brain. pp. 191-206. https://doi.org/10.1016/B978-0-12-385948-8.00013-X

Hawes, Z., Moss, J., Caswell, B., Poliszczuk, D., 2015. Effects of mental rotation training on children's spatial and mathematics performance : A randomized controlled study. Trends Neurosci. Educ. 4, 1-9. https://doi.org/10.1016/j.tine.2015.05.001

Herrera, A., Macizo, P., Semenza, C., 2008. The role of working memory in the association between number magnitude and space. Acta Psychol. (Amst). 128, 225-237. https://doi.org/10.1016/J.ACTPSY.2008.01.002

Hoffmann, D., Hornung, C., Martin, R., Schiltz, C., 2013. Developing number-space associations: SNARC effects using a color discrimination task in 5-year-olds. J. Exp. Child Psychol. 116, 775-791. https://doi.org/10.1016/j.jecp.2013.07.013

Hoffmann, D., Pigat, D., Schiltz, C., 2014. The impact of inhibition capacities and age on number-space associations. Cogn. Process. 15, 329-342. https://doi.org/10.1007/s10339014-0601-9

Holloway, I.D., Ansari, D., 2010. Developmental specialization in the right intraparietal sulcus for the abstract representation of numerical magnitude. J. Cogn. Neurosci. 22, 2627-2637. https://doi.org/10.1162/jocn.2009.21399

Hubbard, E.M., Piazza, M., Pinel, P., Dehaene, S., 2009. Numerical and Spatial Intuitions: A Role for Posterior Parietal Cortex? Cogn. Biol. Evol. Dev. Perspect. mind, brain Behav. 11, 221-246.

Hubbard, E.M., Piazza, M., Pinel, P., Dehaene, S., 2005. Interactions between number and space in parietal cortex. Nat. Rev. Neurosci. 6, 435-48. https://doi.org/10.1038/nrn1684

Huber, S., Klein, E., Moeller, K., Willmes, K., 2016. Spatial-Numerical and ordinal positional associations coexist in parallel. Front. Psychol. 7, 1-13. https://doi.org/10.3389/fpsyg.2016.00438

Hung, Y. hui, Hung, D.L., Tzeng, O.J.L., Wu, D.H., 2008. Flexible spatial mapping of different notations of numbers in Chinese readers. Cognition 106, 1441-1450. https://doi.org/10.1016/j.cognition.2007.04.017

Ikkai, A., Curtis, C.E., 2011. Common neural mechanisms supporting spatial working memory, attention and motor intention. Neuropsychologia 49, 1428-1434. https://doi.org/10.1016/J.NEUROPSYCHOLOGIA.2010.12.020

Imbo, I., Brauwer, J. De, Fias, W., Gevers, W., 2012. The development of the SNARC effect: Evidence for early verbal coding. J. Exp. Child Psychol. 111, 671-680. https://doi.org/10.1016/j.jecp.2011.09.002

Johnson, M.H., 2011. Interactive Specialization: A domain-general framework for human functional brain development? Dev. Cogn. Neurosci. 1, 7-21. 
https://doi.org/10.1016/j.den.2010.07.003

Kanayet, F.J., Mattarella-Micke, A., Kohler, P.J., Norcia, A.M., McCandliss, B.D., Mcclelland, J.L., 2017. Distinct Representations of Magnitude and Spatial Position within Parietal Cortex during Number-Space Mapping. J. Cogn. Neurosci.

https://doi.org/10.1162/jocn_a_01199

Käser, T., Baschera, G.-M., Kohn, J., Kucian, K., Richtmann, V., Grond, U., Gross, M., von Aster, M., 2013. Design and evaluation of the computer-based training program Calcularis for enhancing numerical cognition. Front. Psychol. 4, 489.

https://doi.org/10.3389/fpsyg.2013.00489

Keus, I.M., Jenks, K.M., Schwarz, W. f., 2005. Psychophysiological evidence that the SNARC effect has its functional locus in a response selection stage. Cogn. Brain Res. 24, 48-56. https://doi.org/10.1016/j.cogbrainres.2004.12.005

Kirjakovski, A., Utsuki, N., 2012. From SNARC to SQUARC: Universal Mental Quantity Line? Int. J. Psychol. Stud. 4, 217-227. https://doi.org/10.5539/ijps.v4n2p217

Knops, A., Thirion, B., Hubbard, E.M., Michel, V., Dehaene, S., 2009. Recruitment of an area involved in eye movements during mental arithmetic. Science (80-. ). 324, 1583-1585.

Koten, J.W., Lonnemann, J., Willmes, K., Knops, A., 2011. Micro and macro pattern analyses of fMRI data support both early and late interaction of numerical and spatial information. Front. Hum. Neurosci. 5, 1-12. https://doi.org/10.3389/fnhum.2011.00115

Kucian, K., Grond, U., Rotzer, S., Henzi, B., Sch??nmann, C., Plangger, F., G??1li, M., Martin, E., von Aster, M., 2011. Mental number line training in children with developmental dyscalculia. Neuroimage 57, 782-795. https://doi.org/10.1016/j.neuroimage.2011.01.070

Lammertyn, J., Fias, W., Lauwereyns, J., 2002. Semantic Influences on Feature-Based Attention Due to Overlap of Neural Circuits. Cortex 38, 878-882. https://doi.org/10.1016/S00109452(08)70061-3

Landy, D.H., Jones, E.L., Hummel, J.E., 2008. Why Spatial-Numeric Associations Aren ' t Evidence for a Mental Number Line. Proc. Annu. Meet. Cogn. Sci. Soc. 30.

Leibovich, T., Katzin, N., Harel, M., Henik, A., 2016. From "sense of number" to "sense of magnitude" - The role of continuous magnitudes in numerical cognition. Behav. Brain Sci. 40, 1-62. https://doi.org/10.1017/S0140525X16000960

Leth-Steensen, C., Citta, R., 2016. Bad-good constraints on a polarity correspondence account for the spatial-numerical association of response codes (SNARC) and markedness association of response codes (MARC) effects. Q. J. Exp. Psychol. 69, 482-494. https://doi.org/10.1080/17470218.2015.1055283

Li, M., Lv, H., Abdukerim, Z., Zhang, Y., Qiao, F., Li, Q., 2016. Verbal-Spatial and Visuospatial Coding of the SNARC Effect: A Comparative Study in Cultures With Different Reading Directions. Percept. Mot. Skills. https://doi.org/10.1177/0031512516654500

Lindemann, O., Alipour, a., Fischer, M.H., 2011. Finger Counting Habits in Middle Eastern and Western Individuals: An Online Survey. J. Cross. Cult. Psychol. 42, 566-578. 
https://doi.org/10.1177/0022022111406254

Link, T., Nuerk, H.C., Moeller, K., 2014. On the relation between the mental number line and arithmetic competencies. Q. J. Exp. Psychol. 67, 1597-1613. https://doi.org/10.1080/17470218.2014.892517

Lourenco, S.F., Bonny, J.W., 2016. Representations of numerical and non-numerical magnitude both contribute to mathematical competence in children. Dev. Sci. 1, 1-16. https://doi.org/10.1111/desc. 12418

Lourenco, S.F., Bonny, J.W., Fernandez, E.P., Rao, S., 2012. Nonsymbolic number and cumulative area representations contribute shared and unique variance to symbolic math competence. Proc. Natl. Acad. Sci. U. S. A. 109, 18737-18742. https://doi.org/10.1073/pnas.1207212109

Lourenco, S.F., Longo, M.R., 2010. General Magnitude Respresentation in Human Infants. Psychol. Sci. 21, 873-881. https://doi.org/10.1177/0956797610370158.General

Lowrie, T., Logan, T., Ramful, A., 2017. Visuospatial training improves elementary students' mathematics performance. Br. J. Educ. Psychol. 87, 170-186. https://doi.org/10.1111/bjep.12142

Mapelli, D., Rusconi, E., Umiltà, C., 2003. The SNARC effect: an instance of the Simon effect? Cognition 88, B1-10.

Marghetis, T., Walker, E., Bergen, B.K., Nunez, R., 2011. Making SNAP judgments: Rethinking the spatial representation of number. Proc. 33rd Annu. Conf. Cogn. Sci. Soc. 1781-1786.

Mathieu, R., Epinat-Duclos, J., Sigovan, M., Breton, A., Cheylus, A., Fayol, M., Thevenot, C., Prado, J., 2017. What's Behind a "+" Sign? Perceiving an Arithmetic Operator Recruits Brain Circuits for Spatial Orienting. Cereb. Cortex 1-12. https://doi.org/10.1093/cercor/bhx064

Mayer, E., Martory, M.D., Pegna, A.J., Landis, T., Delavelle, J., Annoni, J.M., 1999. A pure case of Gerstmann syndrome with a subangular lesion. Brain 122, 1107-1120. https://doi.org/10.1093/brain/122.6.1107

McCrink, K., Caldera, C., Shaki, S., 2017. The Early Construction of Spatial Attention: Culture, Space, and Gesture in Parent-Child Interactions. Child Dev. https://doi.org/10.1111/cdev.12781

McCrink, K., Opfer, J.E., 2014. Development of Spatial-Numerical Associations. Curr. Dir. Psychol. Sci. 23, 439-445. https://doi.org/10.1177/0963721414549751

McCrink, K., Shaki, S., 2016. Culturally inconsistent spatial structure reduces learning. Acta Psychol. (Amst). https://doi.org/10.1016/j.cognition.2006.02.005

Mitchell, T., Bull, R., Cleland, A.A., 2012. Implicit response-irrelevant number information triggers the SNARC effect: Evidence using a neural overlap paradigm. Q. J. Exp. Psychol. 65, 1945-1961. https://doi.org/10.1080/17470218.2012.673631

Mix, K.S., Cheng, Y.L., 2012. The Relation Between Space and Math. Developmental and 
Educational Implications. Adv. Child Dev. Behav. 42, 197-243.

https://doi.org/10.1016/B978-0-12-394388-0.00006-X

Mix, K.S., Levine, S.C., Young, C., Hambrick, D.Z., 2016. Separate But Correlated : The Latent Structure of Space and Mathematics Across Development. J. Exp. Psychol. Gen. 145, 12061227.

Moeller, K., Fischer, U., Nuerk, H.-C., Cress, U., 2015. Computers in mathematics education Training the mental number line. Comput. Human Behav. 48, 597-607. https://doi.org/10.1016/j.chb.2015.01.048

Moyer, R.S., Landauer, T.K., 1967. Time required for judgements of numerical inequality. Nature 215, 1519-1520. https://doi.org/10.1038/2151519a0

Muldoon, K., Towse, J., Simms, V., Perra, O., Menzies, V., 2013. A longitudinal analysis of estimation, counting skills, and mathematical ability across the first school year. Dev. Psychol. 49, 250-257. https://doi.org/10.1037/a0028240

Newcombe, N.S., Levine, S.C., Mix, K.S., 2015. Thinking about quantity: The intertwined development of spatial and numerical cognition. Wiley Interdiscip. Rev. Cogn. Sci. 6, 491505. https://doi.org/10.1002/wcs. 1369

Nicholls, M.E.R., Loftus, A.M., Gevers, W., 2008. Look, no hands: A perceptual task shows that number magnitude induces shifts of attention. Psychon. Bull. Rev. 15, 413-418. https://doi.org/10.3758/PBR.15.2.413

Nieder, A., Diester, I., Tudusciuc, O., 2006. Temporal and spatial enumeration processes in the primate parietal cortex. Science (80-. ). 313, 1431-1435.

https://doi.org/10.1126/science. 1130308

Ninaus, M., Moeller, K., Kaufmann, L., Fischer, M.H., Nuerk, H.-C., Wood, G., 2017. Cognitive Mechanisms Underlying Directional and Non-directional Spatial-Numerical Associations across the Lifespan. Front. Psychol. 8, 1-13. https://doi.org/10.3389/fpsyg.2017.01421

Nuerk, H.-C., Iversen, W., Willmes, K., 2004. Notational modulation of the SNARC and the MARC (linguistic markedness of response codes) effect. Q. J. Exp. Psychol. A. 57, 835-63. https://doi.org/10.1080/02724980343000512

Nuerk, H.C., Patro, K., Cress, U., Schild, U., Friedrich, C.K., G??bel, S.M., 2015. How spacenumber associations may be created in preliterate children: Six distinct mechanisms. Front. Psychol. 6, 1-6. https://doi.org/10.3389/fpsyg.2015.00215

Nuerk, H.C., Wood, G., Willmes, K., 2005. The universal SNARC effect: The association between number magnitude and space is amodal. Exp. Psychol. 52, 187-194. https://doi.org/10.1027/1618-3169.52.3.187

Núñez, R., Cooperrider, K., Wassmann, J., 2012. Number Concepts without Number Lines in an Indigenous Group of Papua New Guinea. PLoS One 7, e35662. https://doi.org/10.1371/journal.pone.0035662

Nunez, R., Fias, W., 2015. Ancestral Mental Number Lines: What Is the Evidence? Cogn. Sci. 1-5. https://doi.org/10.1111/cogs. 12296 
Nunez, R., Lakoff, G., 2005. The Cognitive Foundations of Mathematics: The Role of Conceptual Metaphor, in: HANDBOOK OF MATHEMATICAL COGNITION. pp. 109124.

Núñez, R.E., 2011. No Innate Number Line in the Human Brain. J. Cross. Cult. Psychol. 42, 651-668. https://doi.org/10.1177/0022022111406097

Patro, K., Haman, M., 2012. The spatial-numerical congruity effect in preschoolers. J. Exp. Child Psychol. 111, 534-542. https://doi.org/10.1016/j.jecp.2011.09.006

Patro, K., Nuerk, H.C., Cress, U., Haman, M., 2014. How number-space relationships are assessed before formal schooling: A taxonomy proposal. Front. Psychol. 5, 1-6. https://doi.org/10.3389/fpsyg.2014.00419

Pfister, R., Schroeder, P.A., Kunde, W., 2013. SNARC Struggles : Instant Control Over Spatial Numerical Associations. J. Exp. Psychol. Learn. Mem. Cogn. 39, 1953-1958. https://doi.org/10.1037/a0032991

Piaget, J., 1952. The child's conception of number.

Piazza, M., Pinel, P., Le Bihan, D., Dehaene, S., 2007. A Magnitude Code Common to Numerosities and Number Symbols in Human Intraparietal Cortex. Neuron 53, 293-305. https://doi.org/10.1016/j.neuron.2006.11.022

Pinel, P., Piazza, M., Le Bihan, D., Dehaene, S., 2004. Distributed and overlapping cerebral representations of number, size, and luminance during comparative judgments. Neuron 41, 983-993. https://doi.org/10.1016/S0896-6273(04)00107-2

Pitt, B., Casasanto, D., 2014. Experiential origins of the mental number line. Proc. 36 th Annu. Meet. ... 1174-1179.

Posner, M.A., 1980. Orienting of attention. Q. J. Exp. Psychol. 32, 3-25. https://doi.org/10.1080/00335558008248231

Priftis, K., Zorzi, M., Meneghello, F., Marenzi, R., Umiltà, C., 2006. Explicit versus Implicit Processing of Representational Space in Neglect: Dissociations in Accessing the Mental Number Line. J. Cogn. Neurosci. 18, 680-688. https://doi.org/10.1162/jocn.2006.18.4.680

Proctor, R.W., Cho, Y.S., 2006. Polarity correspondence: A general principle for performance of speeded binary classification tasks. Psychol. Bull. 132, 416-442. https://doi.org/10.1037/0033-2909.132.3.416

Proctor, R.W., Xiong, A., 2015. Polarity Correspondence as a General Compatibility Principle. Curr. Dir. Psychol. Sci. 24, 446-451. https://doi.org/10.1177/0963721415607305

Ramani, G.B., Siegler, R.S., 2008. Promoting Broad and Stable Improvements in Low-Income Children's Numerical Knowledge through Playing Number Board Games. Child Dev. 79, 375-394.

Ranzini, M., Dehaene, S., Piazza, M., Hubbard, E.M., 2009. Neural mechanisms of attentional shifts due to irrelevant spatial and numerical cues. Neuropsychologia 47, 2615-2624. https://doi.org/10.1016/j.neuropsychologia.2009.05.011 
Rentzeperis, I., Nikolaev, A.R., Kiper, D.C., van Leeuwen, C., 2014. Distributed processing of color and form in the visual cortex. Front. Psychol. 5, 1-14.

https://doi.org/10.3389/fpsyg.2014.00932

Restle, F., 1970. Speed of adding and comparing numbers. J. Exp. Psychol. 83, 274-278. https://doi.org/10.1037/h0028573

Riello, M., Rusconi, E., 2011. Unimanual SNARC effect: Hand matters. Front. Psychol. 2, 1-11. https://doi.org/10.3389/fpsyg.2011.00372

Riemer, M., Diersch, N., Bublatzky, F., Wolbers, T., 2016. Space, time, and numbers in the right posterior parietal cortex: Differences between response code associations and congruency effects. Neuroimage 129, 72-79. https://doi.org/10.1016/j.neuroimage.2016.01.030

Rinaldi, L., Gallucci, M., Girelli, L., 2016. Spatial-numerical consistency impacts on preschoolers' numerical representation: Children can count on both peripersonal and personal space. Cogn. Dev. 37, 9-17. https://doi.org/10.1016/j.cogdev.2015.10.006

Ristic, J., Kingstone, A., 2006. Attention to arrows: Pointing to a new direction. Q. J. Exp. Psychol. 59, 1921-1930. https://doi.org/10.1080/17470210500416367

Rotondaro, F., Merola, S., Aiello, M., Pinto, M., Doricchi, F., 2015. Dissociation between line bisection and mental-number-line bisection in healthy adults. Neuropsychologia 75, 565576. https://doi.org/10.1016/j.neuropsychologia.2015.07.016

Rugani, R., Kelly, D.M., Szelest, I., Regolin, L., Vallortigara, G., 2010. Is it only humans that count from left to right? Biol. Lett. 6, 290-292. https://doi.org/10.1098/rsbl.2009.0960

Rugani, R., Vallortigara, G., Priftis, K., Regolin, L., 2015. Number-space mappings in the newborn chick resembles humans' mental number line 347, 534-536.

Rusconi, E., Bueti, D., Walsh, V., Butterworth, B., 2011. Contribution of frontal cortex to the spatial representation of number. Cortex 47, 2-13. https://doi.org/10.1016/j.cortex.2009.08.005

Rusconi, E., Dervinis, M., Verbruggen, F., Chambers, C.D., 2013. Critical Time Course of Right Frontoparietal Involvement in Mental Number Space. J. Cogn. Neurosci. 25, 465-483. https://doi.org/10.1162/jocn_a_00330

Rusconi, E., Kwan, B., Giordano, B.L., Umiltà, C., Butterworth, B., 2006. Spatial representation of pitch height: The SMARC effect. Cognition 99, 113-129. https://doi.org/10.1016/j.cognition.2005.01.004

Rusconi, E., Pinel, P., Eger, E., LeBihan, D., Thirion, B., Dehaene, S., Kleinschmidt, A., 2009. A disconnection account of Gerstmann syndrome: Functional neuroanatomy evidence. Ann. Neurol. 66, 654-662. https://doi.org/10.1002/ana.21776

Rusconi, E., Turatto, M., Umiltà, C., 2007. Two orienting mechanisms in posterior parietal lobule: An rTMS study of the Simon and SNARC effects. Cogn. Neuropsychol. 24, $373-$ 392. https://doi.org/10.1080/02643290701309425

Salillas, E., El Yagoubi, R., Semenza, C., 2008. Sensory and cognitive processes of shifts of 
spatial attention induced by numbers: An ERP study. Cortex 44, 406-413. https://doi.org/10.1016/j.cortex.2007.08.006

Santens, S., Gevers, W., 2008. The SNARC effect does not imply a mental number line. Cognition 108, 263-270. https://doi.org/10.1016/j.cognition.2008.01.002

Santiago, J., Lakens, D., 2015. Can conceptual congruency effects between number, time, and space be accounted for by polarity correspondence? Acta Psychol. (Amst). 156, 179-191. https://doi.org/10.1016/J.ACTPSY.2014.09.016

Sasanguie, D., Göbel, S.M., Moll, K., Smets, K., Reynvoet, B., 2013. Approximate number sense , symbolic number processing, or number - space mappings : What underlies mathematics achievement? J. Exp. Child Psychol. 114, 418-431. https://doi.org/10.1016/j.jecp.2012.10.012

Sasanguie, D., Van Den Bussche, E., Reynvoet, B., 2012. Predictors for Mathematics Achievement? Evidence From a Longitudinal Study. Minds, Brain, Educ. 6, 119-128. https://doi.org/10.1111/j.1751-228X.2012.01147.x

Schneider, M., Grabner, R.H., Zurich, E., Paetsch, J., 2009. Mental Number Line, Number Line Estimation, and Mathematical Achievement: Their Interrelations in Grades 5 and 6. J. Educ. Psychol. 101, 359-372. https://doi.org/10.1037/a0013840

Schneider, M., Merz, S., Stricker, J., De Smedt, B., Torbeyns, J., Verschaffel, L., Luwel, K., n.d. Associations of Number Line Estimation with Mathematical Competence: A Meta-analysis. Child Dev.

Schroeder, P.A., Nuerk, H.-C., Plewnia, C., 2017. Space in Numerical and Ordinal Information: A Common Construct? J. Numer. Cogn. 3, 164-181. https://doi.org/10.5964/jnc.v3i2.40

Schuller, A.-M., Hoffmann, D., Goffaux, V., Schiltz, C., 2014. Shifts of spatial attention cued by irrelevant numbers: Electrophysiological evidence from a target discrimination task. J. Cogn. Psychol. 1-17. https://doi.org/10.1080/20445911.2014.946419

Schwarz, W., Keus, I.M., 2004. Moving the eyes along the mental number line: Comparing SNARC effects with saccadic and manual responses. Percept. Psychophys. 66, 651-664. https://doi.org/10.3758/BF03194909

Schwarz, W., Müller, D., 2006. Spatial associations in number-related tasks: A comparison of manual and pedal responses. Exp. Psychol. 53, 4-15. https://doi.org/10.1027/16183169.53.1.4

Shaki, S., Fischer, M.H., 2015. Newborn chicks need no number tricks. Commentary: Numberspace mapping in newborn chick resembles humans' mental number line. Front. Hum. Neurosci. 9. https://doi.org/10.1080/713754266

Shaki, S., Fischer, M.H., 2008. Reading space into numbers - a cross-linguistic comparison of the SNARC effect. Cognition 108, 590-599. https://doi.org/10.1016/j.cognition.2008.04.001

Shaki, S., Fischer, M.H., Petrusic, W.M., 2009. Reading habits for both words and numbers contribute to the SNARC effect. Psychon. Bull. Rev. 16, 328-31. 
https://doi.org/10.3758/PBR.16.2.328

Shaki, S., Petrusic, W.M., Leth-Steensen, C., 2012. SNARC effects with numerical and nonnumerical symbolic comparative judgments: Instructional and cultural dependencies. J. Exp. Psychol. Hum. Percept. Perform. 38, 515-530. https://doi.org/10.1037/a0026729

Shea, D.L., Lubinski, D., Benbow, C.P., 2001. Importance of assessing spatial ability in intellectually talented young adolescents: A 20-year longitudinal study. J. Educ. Psychol. 93, 604-614. https://doi.org/10.1037/0022-0663.93.3.604

Siegler, R.S., 2016. Magnitude knowledge: the common core of numerical development. Dev. Sci. 19, 341-61. https://doi.org/10.1111/desc.12395

Siegler, R.S., Opfer, J.E., 2003. The Development of Numerical Estimation. Psychol. Sci. 14, 237-250. https://doi.org/10.1111/1467-9280.02438

Siegler, R.S., Ramani, G.B., 2009. Playing linear number board games-but not circular onesimproves low-income preschoolers' numerical understanding. J. Educ. Psychol. 101, 545560. https://doi.org/10.1037/a0014239

Siegler, R.S., Thompson, C.A., Schneider, M., 2011. An integrated theory of whole number and fractions development. Cogn. Psychol. 62, 273-296. https://doi.org/10.1016/j.cogpsych.2011.03.001

Silk, T.J., Bellgrove, M.A., Wrafter, P., Mattingley, J.B., Cunnington, R., 2010. Spatial working memory and spatial attention rely on common neural processes in the intraparietal sulcus. Neuroimage 53, 718-724. https://doi.org/10.1016/j.neuroimage.2010.06.068

Simms, V., Clayton, S., Cragg, L., Gilmore, C., Johnson, S., 2016. Explaining the relationship between number line estimation and mathematical achievement: The role of visuomotor integration and visuospatial skills. J. Exp. Child Psychol. 145, 22-33. https://doi.org/10.1016/j.jecp.2015.12.004

Skagerlund, K., Träff, U., 2016. Processing of space, time, and number contributes to mathematical abilities above and beyond domain-general cognitive abilities. J. Exp. Child Psychol. 143, 85-101. https://doi.org/10.1016/j.jecp.2015.10.016

Skagerlund, K., Träff, U., 2014. Development of magnitude processing in children with developmental dyscalculia: Space, time, and number. Front. Psychol. 5, 1-15. https://doi.org/10.3389/fpsyg.2014.00675

Starr, A., Brannon, E.M., 2015. Developmental Continuity in the Link Between Sensitivity to Numerosity and Physical Size. J. Numer. Cogn. 1, 7-20. https://doi.org/10.5964/jnc.v1i1.2

Toomarian, E.Y., Hubbard, E.M., 2018. The Fractions SNARC Revisited: Processing Fractions on a Consistent Mental Number Line. Q. J. Exp. Psychol. 0, 1-37. https://doi.org/10.1080/17470218.2017.1350867

Tudusciuc, O., Nieder, A., 2009. Contributions of Primate Prefrontal and Posterior Parietal Cortices to Length and Numerosity Representation. J. Neurophysiol. 101, 2984-2994. https://doi.org/10.1152/jn.90713.2008 
Tudusciuc, O., Nieder, A., 2007. Neuronal population coding of continuous and discrete quantity in the primate posterior parietal cortex. Proc Natl Acad Sci U S A 104, 14513-14518. https://doi.org/0705495104 [pii] \r10.1073/pnas.0705495104

Tversky, B., Kugelmass, S., Winter, A., 1991. Cross-cultural and developmental trends in graphic productions. Cogn. Psychol. 23, 515-557. https://doi.org/10.1016/00100285(91)90005-9

Umiltà, C., Priftis, K., Zorzi, M., 2009. The spatial representation of numbers: Evidence from neglect and pseudoneglect. Exp. Brain Res. 192, 561-569. https://doi.org/10.1007/s00221008-1623-2

Uttal, D.H., Miller, D.I., Newcombe, N.S., 2013. Exploring and enhancing spatial thinking: Links to achievement in science, technology, engineering, and mathematics? Curr. Dir. Psychol. Sci. 22, 367-373. https://doi.org/10.1177/0963721413484756

Vallortigara, G., Rogers, L.J., 2005. Survival with an asymmetrical brain: advantages and disadvantages of cerebral lateralization. Behav. Brain Sci. 28, 575-89-633. https://doi.org/10.1017/S0140525X05000105

van Dijck, J.-P., Gevers, W., Lafosse, C., Fias, W., 2012. The Heterogeneous Nature of NumberSpace Interactions. Front. Hum. Neurosci. 5, 1-13. https://doi.org/10.3389/fnhum.2011.00182

van Dijck, J.P., Fias, W., 2011. A working memory account for spatial-numerical associations. Cognition 119, 114-119. https://doi.org/10.1016/j.cognition.2010.12.013

van Dijck, J.P., Gevers, W., Lafosse, C., Doricchi, F., Fias, W., 2011. Non-spatial neglect for the mental number line. Neuropsychologia 49, 2570-2583. https://doi.org/10.1016/j.neuropsychologia.2011.05.005

van Galen, M.S., Reitsma, P., 2008. Developing access to number magnitude: A study of the SNARC effect in 7- to 9-year-olds. J. Exp. Child Psychol. 101, 99-113. https://doi.org/10.1016/j.jecp.2008.05.001

Van Opstal, F., Fias, W., Peigneux, P., Verguts, T., 2009. The neural representation of extensively trained ordered sequences. Neuroimage 47, 367-375. https://doi.org/10.1016/j.neuroimage.2009.04.035

Viarouge, A., Hubbard, E.M., McCandliss, B.D., 2014. The cognitive mechanisms of the SNARC effect: An individual differences approach. PLoS One 9. https://doi.org/10.1371/journal.pone.0095756

Wai, J., Lubinski, D., Benbow, C.P., 2009. Spatial ability for STEM domains: Aligning over 50 years of cumulative psychological knowledge solidifies its importance. J. Educ. Psychol. 101, 817-835. https://doi.org/10.1037/a0016127

Walsh, V., 2003. A theory of magnitude: Common cortical metrics of time, space and quantity. Trends Cogn. Sci. 7, 483-488. https://doi.org/10.1016/j.tics.2003.09.002

Wansard, M., Meulemans, T., Geurten, M., 2016. Shedding new light on representational neglect: The importance of dissociating visual and spatial components. Neuropsychologia 
84, 150-157. https://doi.org/10.1016/J.NEUROPSYCHOLOGIA.2016.02.006

Webb, R.M., Lubinski, D., Benbow, C.P., 2007. Spatial ability: A neglected dimension in talent searches for intellectually precocious youth. J. Educ. Psychol. 99, 397-420.

https://doi.org/10.1037/0022-0663.99.2.397

White, S.L.J., Szucs, D., Soltesz, F., 2012. Symbolic number: The integration of magnitude and spatial representations in children aged 6 to 8years. Front. Psychol. 3. https://doi.org/10.3389/fpsyg.2011.00392

Whyte, J.C., Bull, R., 2008. Number games, magnitude representation, and basic number skills in preschoolers. Dev. Psychol. 44, 588-96. https://doi.org/10.1037/0012-1649.44.2.588

Winter, B., Marghetis, T., Matlock, T., 2015a. Of magnitudes and metaphors: Explaining cognitive interactions between space, time, and number. Cortex 64, 209-224. https://doi.org/10.1016/j.cortex.2014.10.015

Winter, B., Matlock, T., Shaki, S., Fischer, M.H., 2015b. Mental number space in three dimensions. Neurosci. Biobehav. Rev. 57, 209-219. https://doi.org/10.1016/j.neubiorev.2015.09.005

Wood, G., Nuerk, H.C., Willmes, K., 2006. Crossed hands and the SNARC effect: A failure to replicate Dehaene, Bossini and Giraux (1993). Cortex 42, 1069-1079. https://doi.org/10.1016/S0010-9452(08)70219-3

Wood, G., Willmes, K., Nuerk, H.-C., Fischer, M.H., 2008. On the cognitive link between space and number: a meta-analysis of the SNARC effect. Psychol. Sci. Q. 4, 489-525. https://doi.org/10.1027/1618-3169.52.3.187

Zanolie, K., Pecher, D., 2014. Number-induced shifts in spatial attention: A replication study. Front. Psychol. 5, 1-10. https://doi.org/10.3389/fpsyg.2014.00987

Zebian, S., 2005. Linkages between Number Concepts, Spatial Thinking, and Directionality of Writing: The SNARC Effect and the REVERSE SNARC Effect in English and Arabic Monoliterates, Biliterates, and Illiterate Arabic Speakers. J. Cogn. Cult. 5, 165-190. https://doi.org/10.1163/1568537054068660

Zorzi, M., Di Bono, M.G., Fias, W., 2011. Distinct representations of numerical and nonnumerical order in the human intraparietal sulcus revealed by multivariate pattern recognition. Neuroimage 56, 674-680. https://doi.org/10.1016/j.neuroimage.2010.06.035

Zorzi, M., Priftis, K., Meneghello, F., Marenzi, R., Umiltà, C., 2006. The spatial representation of numerical and non-numerical sequences: Evidence from neglect. Neuropsychologia 44, 1061-1067. https://doi.org/10.1016/J.NEUROPSYCHOLOGIA.2005.10.025

Zorzi, M., Priftis, K., Umiltà, C., 2002. Brain damage: neglect disrupts the mental number line. Nature 417, 138-139. https://doi.org/10.1038/417138a 